OPEN ACCESS

Edited by:

Suvarna Alladi,

Nizam's Institute of Medical

Sciences, India

Reviewed by:

Judith Aharon Peretz,

Rambam Health Care Campus, Israe

Edward N. Wilson,

Stanford University, United States

*Correspondence:

Claudia Duran-Aniotz

Claudia.Duran@uai.cl

Andrea Slachevsky

Andrea.Slachevsky@uchile.c

tThese authors have contributed equally to this work

Specialty section:

This article was submitted to Dementia and Neurodegenerative Diseases, a section of the journal Frontiers in Neurology

Received: 02 February 2021 Accepted: 27 May 2021

Published: 24 June 2021

Citation:

Duran-Aniotz C, Orellana $P$, Leon Rodriguez T, Henriquez $F$

Cabello V, Aguirre-Pinto MF,

Escobedo T, Takada LT,

Pina-Escudero SD, Lopez O,

Yokoyama JS, Ibanez A, Parra MA and Slachevsky A (2021) Systematic Review: Genetic, Neuroimaging, and Fluids Biomarkers for Frontotemporal

Dementia Across Latin America Countries. Front. Neurol. 12:663407.

doi: 10.3389/fneur.2021.663407

\section{Systematic Review: Genetic, Neuroimaging, and Fluids Biomarkers for Frontotemporal Dementia Across Latin America Countries}

\author{
Claudia Duran-Aniotz ${ }^{1,2 * t}$, Paulina Orellana ${ }^{1,2 \dagger}$, Tomas Leon Rodriguez ${ }^{3,4}$, \\ Fernando Henriquez ${ }^{5,6}$, Victoria Cabello ${ }^{5,6}$, María F. Aguirre-Pinto ${ }^{6}$, Tamara Escobedo ${ }^{1,2}$, \\ Leonel T. Takada ${ }^{7}$, Stefanie D. Pina-Escudero ${ }^{8,9}$, Oscar Lopez ${ }^{10,11}$, Jennifer S. Yokoyama ${ }^{8,9}$, \\ Agustin Ibanez ${ }^{1,2,3,8,12}$, Mario A. Parra ${ }^{13}$ and Andrea Slachevsky ${ }^{4,5,6,7,14 *}$ \\ ${ }^{1}$ Latin American Institute for Brain Health (BrainLat), Universidad Adolfo Ibanez, Santiago, Chile, ${ }^{2}$ Center for Social and \\ Cognitive Neuroscience (CSCN), School of Psychology, Universidad Adolfo Ibanez, Santiago, Chile, ${ }^{3}$ Trinity College, Global \\ Brain Health Institute, Dublin, Ireland, ${ }^{4}$ Memory and Neuropsychiatric Clinic (CMYN) Neurology Department, Hospital del \\ Salvador and Faculty of Medicine, University of Chile, Santiago, Chile, ${ }^{5}$ Neuropsychology and Clinical Neuroscience \\ Laboratory (LANNEC), Physiopathology Department - Institute of Biomedical Sciences (ICBM), Neuroscience and East \\ Neuroscience Departments, Faculty of Medicine, University of Chile, Santiago, Chile, ${ }^{6}$ Geroscience Center for Brain Health \\ and Metabolism (GERO), Santiago, Chile, ${ }^{7}$ Cognitive and Behavioral Neurology Unit - Department of Neurology, University of \\ São Paulo, São Paulo, Brazil, ${ }^{8}$ Global Brain Health Institute (GBHI), University of California San Francisco (UCSF), San \\ Francisco, CA, United States, ${ }^{9}$ UCSF Department of Neurology, Memory and Aging Center, UCSF, San Francisco, CA, \\ United States, ${ }^{10}$ Department of Neurology, School of Medicine, University of Pittsburgh, Pittsburgh, PA, United States, \\ ${ }^{11}$ Department of Psychiatry, School of Medicine, University of Pittsburgh, Pittsburgh, PA, United States, ${ }^{12}$ Cognitive \\ Neuroscience Center (CNC), Universidad de San Andrés, \& National Scientific and Technical Research Council (CONICET), \\ Buenos Aires, Argentina, ${ }^{13}$ School of Psychological Sciences and Health, University of Strathclyde, Glasgow, \\ United Kingdom, ${ }^{14}$ Department of Neurology and Psychiatry, Clínica Alemana-Universidad del Desarrollo, Santiago, Chile
}

Frontotemporal dementia (FTD) includes a group of clinically, genetically, and pathologically heterogeneous neurodegenerative disorders, affecting the fronto-insular-temporal regions of the brain. Clinically, FTD is characterized by progressive deficits in behavior, executive function, and language and its diagnosis relies mainly on the clinical expertise of the physician/consensus group and the use of neuropsychological tests and/or structural/functional neuroimaging, depending on local availability. The modest correlation between clinical findings and FTD neuropathology makes the diagnosis difficult using clinical criteria and often leads to underdiagnosis or misdiagnosis, primarily due to lack of recognition or awareness of FTD as a disease and symptom overlap with psychiatric disorders. Despite advances in understanding the underlying neuropathology of FTD, accurate and sensitive diagnosis for this disease is still lacking. One of the major challenges is to improve diagnosis in FTD patients as early as possible. In this context, biomarkers have emerged as useful methods to provide and/or complement clinical diagnosis for this complex syndrome, although more evidence is needed to incorporate most of them into clinical practice. However, most biomarker studies have been performed using North American or European populations, with little representation of the Latin American and the Caribbean $(\llcorner A C)$ region. In the LAC region, there are additional challenges, 
particularly the lack of awareness and knowledge about FTD, even in specialists. Also, LAC genetic heritage and cultures are complex, and both likely influence clinical presentations and may modify baseline biomarker levels. Even more, due to diagnostic delay, the clinical presentation might be further complicated by both neurological and psychiatric comorbidity, such as vascular brain damage, substance abuse, mood disorders, among others. This systematic review provides a brief update and an overview of the current knowledge on genetic, neuroimaging, and fluid biomarkers for FTD in LAC countries. Our review highlights the need for extensive research on biomarkers in FTD in LAC to contribute to a more comprehensive understanding of the disease and its associated biomarkers. Dementia research is certainly reduced in the LAC region, highlighting an urgent need for harmonized, innovative, and cross-regional studies with a global perspective across multiple areas of dementia knowledge.

\section{Keywords: frontotemporal dementia, genetics, neuroimaging, fluid biomarkers, Latin America}

\section{INTRODUCTION}

Dementia in Latin America and the Caribbean (LAC) countries has become a major challenge (1-3). The World Neurology Congress has highlighted that dementia in LAC is a major public health issue with a predicted four-fold increase of its prevalence by $2050(4,5)$. This predicted growth, which is partially due to the increase in life expectancy (6), calls for better diagnostic procedures. The underdiagnosis of dementia in LAC remains a challenge (2). Barriers to diagnosis in the region include inadequate training $(7,8)$, especially among primary care physicians $(2,9)$, together with insufficient access to both healthcare and specialized services such as neuropsychological assessment $(2,6)$.

Epidemiological studies from the LAC region are scarce and existing evidence is limited, nevertheless making only modest contributions to global prevalence figures (10). Most of the literature available on the epidemiology of dementia comes from North American and European cohorts. The most extensive studies on the prevalence of dementia in LAC countries identified frequency rates similar to those reported by western and eastern countries (11-13). Among neurodegenerative dementia, Alzheimer's disease dementia (ADD) and Lewy body dementia are the leading cause of dementia, following by Frontotemporal dementia (FTD), the third most common form of dementia across all age groups, after, and is a leading cause of early-onset

\footnotetext{
Abbreviations: $\mathrm{A} \beta$, amyloid-beta peptides; $\mathrm{AD}$, Alzheimer's disease; AnxA1, Annexin A1; bvFTD, behavioral variant of frontotemporal dementia; C9orf72, chromosome 9 open reading frame 72; COEP-UFMG, Ethics Committee of the Federal University of Minas Gerais; CSF, cerebrospinal fluid; EDTA, ethylenediaminetetracetic acid; FAST, Functional Assessment Staging; GRN, progranulin; hsCRP, high sensitivity $\mathrm{C}$ reactive protein; HWE, Hardy-Weinberg equilibrium; IATI, INNOTEST amyloid tau index; IL, interleukin; LX4, lipoxin A4; MAPT, microtubule-associated protein tau; $\mathrm{MCI}$, mild cognitive impairment; NF, nuclear factor; NFTs, neurofibrillary tangles; PBMCs, peripheral blood mononuclear cells; PCR-RFLP, polymerase chain reaction-restriction fragment length polymorphism; SNP, single nucleotide polymorphism; SPM, specialized pro-resolving mediator; TDP-43, TAR DNA-binding protein 43; TGF, transforming growth factor; TNF, tumor necrosis factor.
}

dementia $(14,15)$, with a prevalence ranging from 3 to $26 \%$ described in North America and European populations $(16,17)$.

FTD is an insidious neurodegenerative clinical syndrome characterized by progressive deficits in behavior, executive function, and language $(16,18,19)$. FTD is often underdiagnosed, due primarily to the lack of awareness as well as clinical overlap with psychiatric disorders $(15,20)$. Although the impact of FTD on LAC countries seems to mirror that of developing countries, barriers to the diagnosis of and post-diagnostic support for this type of dementia differ across such countries $(2,3)$.

Regarding clinical diagnosis, as mentioned, FTD is often underdiagnosed $(15,20,21)$. FTD symptoms typically start between the ages of 40 and 65 in the majority of cases, but it can also occur in younger and older individuals $(16,22)$. In LAC, the most common approach is to rely solely on clinical criteria for diagnosis. Unfortunately, for many clinical subtypes of FTD, there is only a modest correlation between the clinical features and the underlying neuropathology of the disease. Other diagnostic support such as specialized neuropsychological services and/or structural and functional neuroimaging studies are less readily available in the region (2). These well-known limitations have traditionally led to a higher rate of missed diagnosis and when is posed to significant delay in FTD diagnosis, which increases the subsequent burden on caregivers $(23,24)$. Pathologically, post mortem brains of people who had FTD are characterized with frontotemporal lobar degeneration (FTLD) and intracellular depositions of three main proteins: RNA-binding protein TDP-43 ( 50\%), microtubule-associated protein Tau $(\sim 40 \%)$, and, in rare cases, RNA-binding protein (FUS, 5\%) (25). Importantly, FTD has a strong genetic component, with up to $40 \%$ of cases having a family history of dementia, psychiatric disease, or motor symptoms, and $20-30 \%$ of cases having an autosomal dominant pattern $(26,27)$. Mutations in three major genes have been described: C9orf72 (chromosome 9 open reading frame 72), MAPT (microtubule-associated protein tau), and GRN (progranulin) discussed below in this review. 
Biomarkers, defined as a characteristic that is objectively measured and evaluated as an indicator of normal biological processes, pathogenic processes (28), have emerged as promissory methods to provide and/or complement clinical diagnosis for this complex syndrome, although most evidence is needed to incorporate most of them in the routine clinical practice (29-31). Biomarkers have been currently classified in three main topics including genetic, neuroimaging, and fluid biomarkers $(28,32)$. In FTD, diagnostic biomarkers could help discriminate between individuals with FTD, control individuals, and individuals with other neurodegenerative diseases including ADD, as has been described in LAC cases (3). Biomarkers could also help differentiate between clinical, genetic, or pathological subtypes. Other biomarkers could also be used to tailor pharmacological treatment or determinate prognosis (30).

The study of biomarkers in FTD requires sophisticated procedures that only a few research centers have access to in LAC. Moreover, biomarker measurements or research are not funded by public health $(2,3)$. In this scenario, new peripheral biomarkers constitute a promising possibility to implement, for e.g., fluid biomarkers because of their accessibility, reduced cost, and easy management in our LAC region. Nevertheless, the use of biomarkers from fluids is also scarce, currently assessed only for research purposes (3). In addition, neuroimaging techniques are the most expensive and least available, only accessible in specialized medical centers in large cities in LAC. Furthermore, the reliability of available biomarkers, not only in LAC, is limited to centers specialized in dementia, such as memory clinics, where there is more experience in the accurate diagnosis of dementia. Another barrier present in LAC countries is that their validity has not been studied in native populations of each country, given the existing ancestry and genetic mix that represent each LAC country $(1,2)$. For example, genetic studies in Latino, mixed, or indigenous populations represent only $3 \%$ of studies of polygenic risk (3).

Considering the impact of FTD on LAC and the barriers to diagnosis of this progressive neurodegenerative disease, the advent of promising biomarkers (genetic, neuroimaging, and fluid-based) that can enhance diagnostic accuracy and help overcome outstanding needs could have a significant impact on this region. This review aims to update the knowledge base on biomarker development for FTD, with an emphasis on published studies from LAC and highlights the need for further development of FTD biomarkers that can be generalized to broader settings and diverse populations.

\section{MATERIALS AND METHODS}

\section{Database Search}

A systematic search of the online literature was carried out targeting journals indexed by PubMed Central, Redalyc, Scopus, and SciElo databases. Pub-Med Central corresponds to the digital archive of the United States National Institutes of Health and it was selected for its scope and importance in the biomedical and life sciences; this database allows access to free material but the use of the material is subject to copyright and/or license terms. Redalyc is an academic project promoted by the Autonomous
University of Mexico, in collaboration with other institutions, for the dissemination in Open Access of the scientific publishing activity that occurs in and on Ibero-America; and it was selected for its reach in regional populations. Scopus is a bibliographic database of abstracts and citations of scientific journal articles, which are peer-reviewed. This database was selected for its antiquity (1966) and scope since it is sponsored by Elsevier. SciELO is a Brazilian project that promotes the development and operation of Latin American collections for all areas of knowledge, with publications preferably in English, but also in other languages. It was elected for indexing many national and Latin American journals.

To identify potentially eligible studies related to FTD cognitive dysfunction biomarkers, the PRISMA Checklist and PRISMA Statement for Reporting Systematic Reviews and Meta-Analyses was followed, to have a validated and consensual research methodology (33). Two of the authors (MFA and PO) independently searched for articles associated with the following keywords in English: [(Biomarkers) AND (dementia)] OR [(Biomarkers) AND (frontotemporal dementia)] OR [(Biomarkers) AND (frontotemporal dementia behavioral variant)], and then, the procedure was reproduced with the same keywords, translated to Spanish and Portuguese. Those languages were selected because they correspond to the main languages used in Latinamerica, therefore ensuring to include all the Lan American research. Other languages such as french or german were not included, since those papers, despite having Latin American authors, were most probably not based on Latin American population. Initially, the search keys used considered the other clinical patterns of FTD, however in previously exploratory search, only the behavioral variant showed results based on the systematic review formula, for which it was decided to limit the search to the behavioral variant.

\section{Eligibility Criteria and Study Selection}

Studies were considered eligible for data extraction if they meet the following inclusion criteria: original peer-reviewed articles (empirical, quantitative, longitudinal studies, follow-up studies, neuroimaging studies, randomized controlled trials, quasi-randomized controlled trials, cross-sectional studies, longitudinal studies) written in Spanish, English or Portuguese; published between January 2000 until November 2020, based on human Latin American populations, considering samples with FTD pathological characteristics, which their contents were about genetic, neuroimaging and fluid biomarkers. If some of the results found were still in press and could be checked by title and abstract, they were included too for the full-text review, by contacting the authors. No particular diagnostic criteria were required for the samples to be included because the main objectives of some potential results might be comparing them.

The exclusion criteria considered were: studies with no LA population samples, studies conducted with non-human animals, and studies written in a language other than those previously referred. We considered excluded from our investigation model: prospective studies, interview studies, retrospective studies, clinical and treatment trials, qualitative studies, mathematical modeling, experimental replications, scientific simulations, field 
studies, focus groups, non-clinical case studies, literature reviews, systematic reviews, and meta-analyses.

\section{Process of Selection}

In the first stage, MFA and PO searched for the selected keywords using boolean operators. With these first results, in a second stage, the articles were reviewed and selected according to their titles; from here, those who met the search words and/or the eligibility inclusion criteria were considered for the next stage. In the third stage, the abstracts and the full texts were read by PO and MFA to ensure papers met the criteria for sample descriptors, language, type of study, and contents. When the third stage was completed, the exhaustive review of each paper for the final selection was made by three authors (MA$\mathrm{P}, \mathrm{PO}$, and TL). Disagreements were resolved by discussion between the three authors and, in case of disagreement, a fourth opinion was sought from the other authors for a final decision. Finally, the resulting sample of papers was divided between the other authors for the data analysis and synthesis. The flowchart in Figure 1 illustrates the sequence of actions and outcomes.

\section{Data Synthesis}

MFA recorded specific data for each study (Table 1) including first all relevant citation information [author name(s), year of publication, Digital Object Identifier (DOI), and the databased site where the article can be found] to facilitate the individual search for readers. Secondly, the country from which the study sample was recruited is reported with the purpose of highlighting research status in different localities. Third, each paper was reviewed and classified by the general biomarker technique used in its methods (category in the table): biomarkers (fluid-based), neuroimaging, and genetics. This was done to help readers categorize the amount of information available for each modality. The specific technique used in each category was presented in the specification column, highlighting the methodological approaches most often used in Latin American and Caribbean research. Finally, if the selected article provided information about the connection of said biomarkers to a particular cognitive domain, this was reported in the cognitive column. This data summary provides a high-level overview of the research occurring in LAC and allows reflection on the utility of biomarker information and translational research to the biomedical field.

\section{RESULTS}

After performing the PRISMA analysis, our search identified 21 studies on FTD and biomarkers in the LAC region. The selection process is depicted in the flowchart in Figure $\mathbf{1}$.

\section{Biomarkers}

A biomarker is defined as an objectively measurable indicator of a biological state or pathological condition. A biomarker must be reproducible, stable, available to a large part of the population and reflect relevant disease processes (28). Biomarkers have the

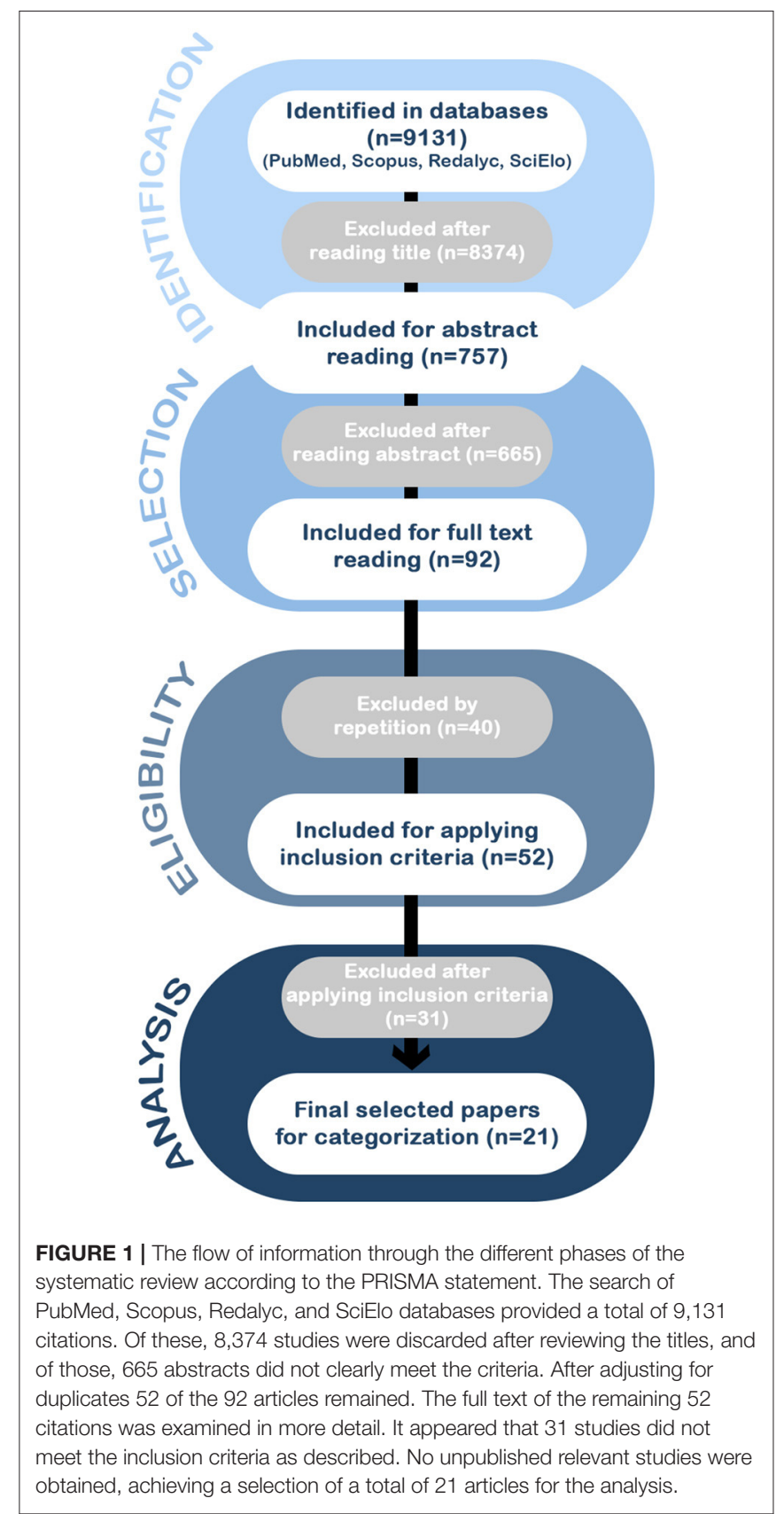

potential to be useful in dementia in several ways, including distinguishing different aspects of underlying pathology, detection of pre-symptomatic pathological changes, predicting decline or conversion between clinical disease states, and monitoring disease progression and response to treatment (32). As mentioned, the diagnosis of FTD is particularly challenging because the relationship between clinical symptoms, pathology, and genetic causes are complex $(31,55,56)$. In this scenario, biomarkers represent a potentially informative diagnostic tool for this condition. However, almost all biomarker studies in FTD have been performed in North American and European 
TABLE 1 | Papers resume table.

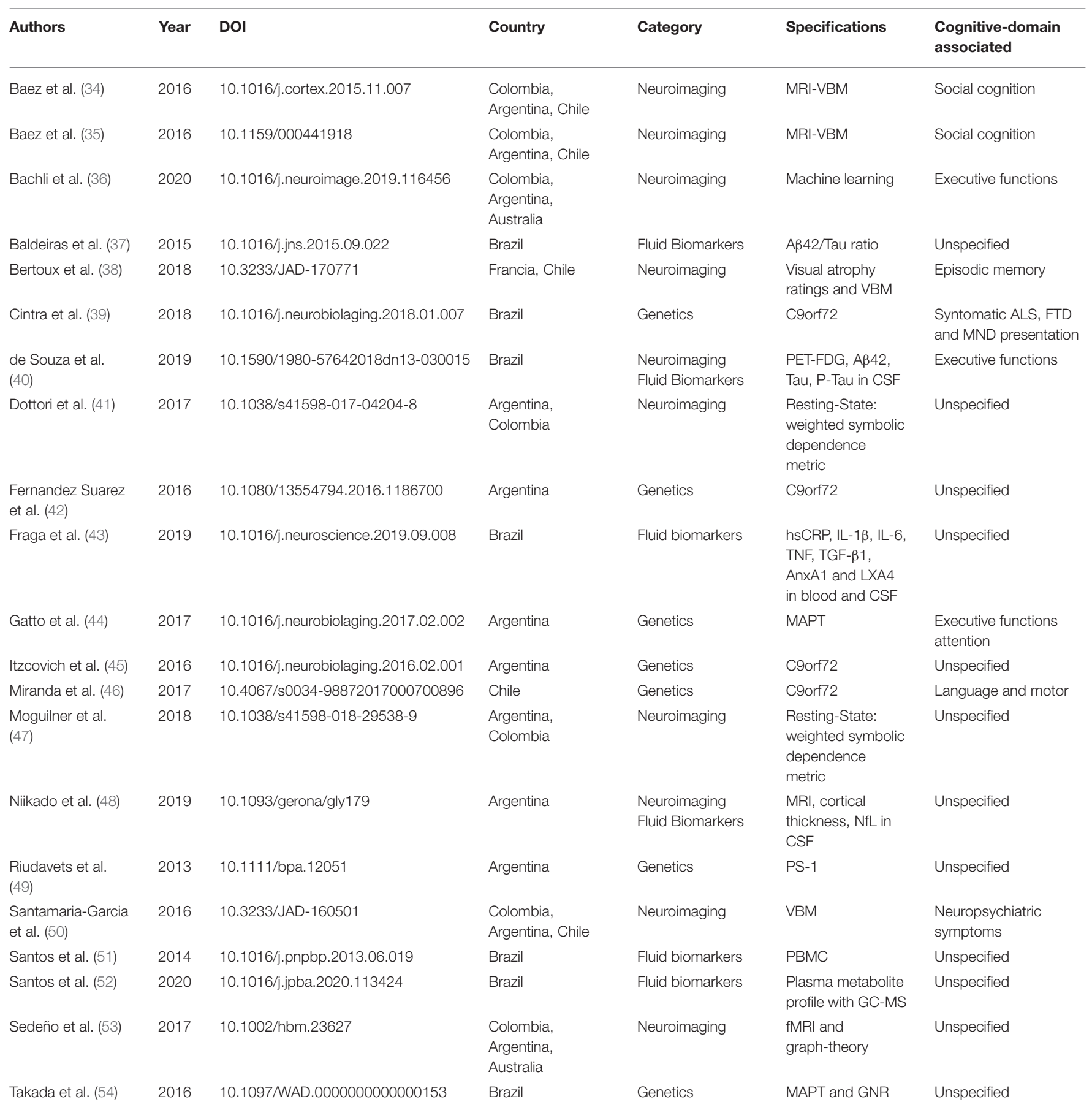

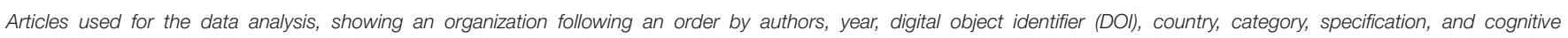
domain associated.

populations (57), neglecting LAC countries (3). Here, we provide a brief update and the current state of knowledge on genetic, neuroimaging, and fluid biomarkers for FTD in the LAC region.

\section{Genetics Biomarkers for FTD in LAC}

A strong genetic component has been observed in FTD, where $20-30 \%$ of cases have an autosomal dominant inheritance (26, $27,58)$. This inheritance is mainly due to mutations in the genes 
C9orf72, GRN, and MAPT (59). Mutations in MAPT and GRN each account for $5-11 \%$ of total FTD cases (26). In 2011, a novel pathogenic expansion intronic to the gene C9orf72 was identified, which has subsequently been found to be the most common genetic cause of FTD in Northern Europe and North America (60-62). In addition, mutations have been identified in other genes such as VCP, CHMP2B, TARDBP, FUS, EXT2, SQSTM1, CHCHD10, TBK1, OPTN, CCNF, TIA1 in rare cases of FTD (63).

\section{C9orf72}

A hexanucleotide repeat (GGGGCC, $\mathrm{G}_{4} \mathrm{C}_{2}$ ) expansion in chromosome 9 open reading frame 72 (C9orf72) [GenBank: JN681271] was discovered to likely be the most frequent genetic cause of bvFTD, FTD with motor neuron disease (FTD-MND), and amyotrophic lateral sclerosis (ALS) in some populations $(60,62)$. In Europe and North America, the C9orf72 expansion accounted for nearly $40 \%$ of familial and $8 \%$ of sporadic ALS, as well as $25 \%$ of familial and $6 \%$ of sporadic FTD cases (64). In contrast, the frequency was extremely rare in Asian $(65,66)$ and Middle Eastern countries (67).

Regarding the genetic situation in the LAC, some studies of C9orf72 have been described in Chile, Argentina, and Brazil. In Chile, a case report of a family carrier of C9orf72 mutation affected by non-fluent aphasia leading to mutism and mild parkinsonism was described (46). In Argentina, the first case with FTD and C9orf72 mutation was reported in 2016 (42). A Brazilian kindred with FTD and FTD-ALS was reported in 2012, in which significant heterogeneity across different family members was seen and subtle behavioral changes were observed decades before a diagnosis of bvFTD was made (68). Later, the first characterization of C9orf72 expansion in a group of patients was carried out in Latin America (45). Thirty-three patients with FTD and 50 patients with Amyotrophic Lateral Sclerosis. Hexanucleotide expansion was identified at a frequency of $18.2 \%$ in the FTD group while expansion explains $37.5 \%$ of the familial cases. In the group with ALS, the expansion was identified in 1 patient with a family history of the 3 cases studied, while in sporadic ALS the expansion was identified in $2.1 \%$ of the patients (45). In Brazil, a group of 404 patients with ALS and 67 with FTD were assessed forC9orf72 pathogenic expansion. Pathogenic repeat expansions were found in $11.8 \%$ of familial ALS and $3.6 \%$ of sporadic ALS. In the cases of FTD, the pathogenic expansion was identified in $7.1 \%$ of the familial cases and was not detected in sporadic cases. Among the 35 cases of ALS with the C9orf72 mutation, $25.7 \%$ also presented clinically with FTD; and among the 15 FTD mutation carriers, $20 \%$ also had ALS (39).

\section{MAPT}

Microtubule Associated Protein Tau (MAPT) encodes tau proteins involved in microtubule stabilization and assembly. Mutations in this gene cause tau splicing alterations, promote tau cytoplasmic aggregation, or cause tau hyperphosphorylation, which generates microtubule instability $(18,69)$. Mutations in MAPT in FTD have been reported at $17.9 \%$ in a British study and $4.7 \%$ in a French study $(70,71)$. Interesting, MAPT mutations were absent in Korean and Indian cohorts $(72,73)$. Regarding LAC status, in Argentina, a missense mutation p.P301L in exon
10 of the MAPT gene has been described in a large family with a behavioral variant of FTD (44). In Brazil, 55 patients with behavioral variant FTD, 11 with semantic variant PPA, and 10 with non-fluent variant PPA were studied. In that study, MAPT mutations were found in $7.1 \%$ of the entire cohort and in $10.5 \%$ of the familial cases (54).

\section{GRN}

Progranulin protein is encoded by the GRN gene and is expressed in a wide variety of cell types both in the periphery and in the central nervous system (74). This protein has several functions including activation of signaling cascades for neuronal growth, inflammation, and wound repair $(18,19,74)$. The frequency of GRN mutations in FTD has been reported to be $3-15 \%$ in studies in North America and Europe cohorts $(60,70,71,75-78)$, while in Asia, the frequency was $0-1.6 \%(72,73,79)$. Among family cases, frequencies of $24.8 \%$ have been described in northern Italy, $20 \%$ in the UK, and $14 \%$ in France $(70,71,75)$. In Brazil, the same cohort described above also assessed GRN and identified mutations in $9.6 \%$ of the total cases, including $31.5 \%$ of the familial cases, making GRN mutations the most common form of monogenic FTD in that sample (54).

\section{TARDBP}

Gene codified for a protein called transactive response DNA binding protein $43 \mathrm{kDA}$ (TDP-43). This protein has functions such as RNA transcription, splicing, transport, and stability (80-82). Mutations in TARDBP are not common. Mutations in TARDBP are identified mostly in familial ALS patients, but also in sporadic FTD, AD, and PD cases (83-87). In Brazil, Machado-Costa identified a TARDBP mutation in a 54-year-old patient diagnosed with semantic dementia. This mutation was identified in the exon 6 of TARDBP corresponding to a p.I1383V mutation (88).

\section{Presenilin-1}

PSN-1 gene is frequently mutated in familial $\operatorname{AD}(89,90)$, however, some mutations in this gene can be associated with an FTD phenotype (91). PSN-1 mutations may be associated with FTD phenotype in a minority of cases $(91,92)$. An Argentine family with FTD history was studied and was identified with the M146V mutation in PSN-1. This family showed histopathological changes of both Pick's disease and AD (49).

\section{TREM2}

Homozygous or compound heterozygous mutations of TREM2 have been associted to Nasu-Hakola disease which is characterized by bone involvement with an early-onset FTD phenotype $(93,94)$. These mutations of TREM2 have also been associated with FTD-like presentations without bone involvement $(95,96)$. Patients with FTD-like syndromes have been identified harboring homozygous or compound heterozygous mutations in TREM2 including p.Q33X, p.Y38C, p.R47C, p.R62C, p.T66M, p.D86V, p.D87N, p.D134G, among others $(93,95-100)$. Also, for heterozygous mutations in TREM2, association studies have been performed to determine the conferred risk of each variant. Two meta-analyses of rare variants in TREM2 found that the p.R47H and p.T96K 
variants confer a 2- to 3-fold increased risk of FTD in European populations $(101,102)$. In a Colombian family that presented the bvFTD phenotype (and no bone phenotype) was identified TREM2 p.W198X mutation in homozygosity. The clinical phenotype identified in the Colombian family with homozygous TREM2 mutations suggests that the genetic basis of monogenic bvFTD in LAC may be more heterogeneous than the families observed in northern European populations (103).

\section{Neuroimaging and Neurocognitive Studies in FTD}

Classically, FTD cases show frontotemporal and insular atrophy in structural neuroimaging, with Magnetic Resonance Imaging (MRI) (104). In functional neuroimaging including positron emission tomography (PET) or single-photon emission computed tomography (SPECT), hypometabolism and hypoperfusion have been described (105), suggesting the involvement of either structural and/or functional impairment of the frontal lobe in the pathogenesis of FTD (19). Recent advances in the study of neuroimages have incorporated new modalities such as diffusion tensor imaging (DTI), resting-state functional MRI, arterial spin labeling (ASL), and tau PET imaging, allowing investigation of connectivity and molecular changes in different clinical populations (105). Aiming to understand the application of neuroimaging in FTD, several LAC teams have described novel techniques to further understand the underlying pathology of FTD and to help in the differential diagnosis. Here, we describe how neuroimaging has allowed us to study the neural bases of cognitive deficits in FTD using different techniques.

\section{MRI Studies}

\section{Structural}

The neuroanatomical correlates of different cognitive tasks were used to evaluate specific symptoms of FTD, to look for the pathogenic substrate of that clinical manifestation. A multinational team of researchers, including participants from Chile and France, aimed to identify and discriminate the structural anatomical markers of episodic memory impairment in bvFTD, comparing those patients with $\mathrm{AD}$ patients and healthy controls, finding that impairment of medial/lateral temporal atrophy is associated with memory deficits (38).

Social cognition deficits seem to be a critical marker of the disease. Reports from LAC in this domain have shown neurocognitive deficits in FTD related tofacial emotion recognition (106-109), empathy $(34,110-112)$, theory of mind $(106,107,112)$, moral judgment $(35,113)$, moral emotions $(114)$, and interoception (115).

A multinational team of researchers from Argentina, Chile, and Colombia looked for a structural correlate of the moral judgment impairment often seen in bvFTD, finding that in bvFTD patients, judge harm permissible had an inverted relationship with the gray matter volume in the precuneus, thus implying that processing intentions and outcomes for moral judgments rely on regions beyond the Ventromedial Prefrontal Cortex (35). The same group also described that in bvFTD patients, impairment in intentionality comprehension was associated with atrophy on limbic structures like the amygdala and anterior paracingulate cortex, while impairment in empathic concern was associated with atrophy of the orbitofrontal cortex. This is one of the first LAC studies to provide a structural base for the core neurocognitive deficit in FTD (34). The aim of the previous study was mainly to find a structural correlate of symptoms. No description of the accuracy of these methods was described, to use it, for example, as a diagnostic biomarker. However, the authors propose further research is needed and could eventually have other uses, such as diagnosis clarification (34).

The contextual fluctuation different social abilities seems to be a hallmark of FTD (116-120), reported impaired in FTD populations from LAC $(121,122)$. Many of these contributions from LAC have evidenced a multi-feature framework of social cognition in FTD, connecting behavior, electrophysiology, and multimodal neuroimaging (50, 53, 115, 123-126).

Research that used machine-learning algorithms (computational-decision methods) to identify bvFTD and $\mathrm{AD}$, was carried out by a team from Argentina and Colombia, in collaboration with one team from Australia (36). This team was the first one to validate the importance of cognitivebehavioral assessment and neuroanatomical measures combined to identify bvFTD and $\mathrm{AD}$ from controls (36). In addition, the combined methods showed high rates of classification (>91\%) and prediction ( $>91 \%$ ) of $\mathrm{AD}$ and bvFTD in new cohorts. These results demonstrate the importance of the application of computer methods combined with cognitive screening assessment (global cognition and executive function) and brain atrophy volume (voxel-based morphometry from fronto-temporo-insular regions in bvFTD) (36).

\section{Functional Connectivity}

In the field of neuroimaging, functional connectivity is a very sensitive tool that is becoming increasingly popular. Functional connectivity is defined by Friston "as the temporal coincidence of spatially distant neurophysiological events" (127). In LAC, this technique had no gold standard reported until a group from Argentina conducted a multicenter analysis of functional imaging in bvFTD (53). Their multidimensional approach involved fMRI and Graph theory to yield a gold-standard that can aid in the distinction between bvFTD and healthy controls. To evaluate Functional connectivity several analyses were performed: seed analysis, inter-regional connectivity, and graph-theory approaches. They found interesting results indicating that frontal and temporal areas showed less integrated and interconnected areas in FTD as described by Freeman "indicate the number of shortest paths that pass through a node and link the other node pairs across the network" (128). In addition, the authors showed in 148 patients that graphtheory based on weighted matrices could distinguish between bvFTD and other neurodegenerative diseases across centers, highlighting this technique as a potential gold standard to analyze brain networks in bvFTD. Moreover, betweenness centrality and graph theory are both methods able to detect brain connectivity abnormalities and discriminate bvFTD from healthy controls (53). 


\section{Summary of Neuroimaging and Neurocognitive Studies}

The research for new and early biomarkers for neurodegenerative diseases, such as FTD, is one of the main goals of many research groups. All the presented research related to neuroimaging has very high relevance. Search for biomarkers for early diagnosis of neurodegenerative disease is pivotal and neuroimaging methods are potential sensitive biomarkers for being used in the population of the LAC region. The majority of the LAC research described in our review is based on structural neuroimaging, and functional imaging. Those biomarkers appear to be more affordable in the LAC context and further research is needed to expand these biomarkers across LAC, allowing a better diagnosis in a limited budget context. Nevertheless, several other biomarkers are being used around the world, including functional imaging allowing in vivo imaging of proteins, DTI allowing to evaluate the connection between lobes, among others (105). They have provided important insights into FTD pathology, especially in HIC $(104,129)$, therefore an effort should also be done to increase the access to those resources for special cases.

\section{Electroencephalographic Studies}

A multicenter study, conducted by a team from Argentina and Colombia, developed a novel non-linear association method to evaluate the ability to identify patients with bvFTD and healthy controls based on resting-state functional connectivity. This method called weighted Symbolic Dependence Metric (wSDM) inspired by EEG studies and based on machine learning, proved to be superior to linear measurements (R Pearson) widely used in the identification of functional connectivity in patients with bvFTD $(41,47)$. Another similar non-linear connectivity method has been proven robust to classify FTD patients based on the dynamical fluctuation assessed with machine learning (130). This study also provided evidence of generalization of classification to both LAC and High-Income Countries (HIC) datasets. Although few studies with EEG were founded, EEG is a cheap and accessible method of research, especially useful for LMIC like in Latin America.

\section{FTD-Related Fluid Biomarkers}

Cerebrospinal fluid (CSF) and blood are the most frequent fluids which have been described or studied as a diagnostic tool in dementias (131). Here, we will provide the most recent knowledge of the use of fluids biomarkers in LAC cohorts suffering from FTD.

\section{Neurofilament Light Chain}

$\mathrm{NfL}$ is a component of the neuronal cytoskeleton, which is involved in structural support, transport, and neurotransmission in neurons (132). NfL is released into the CSF and blood when neurodegeneration occurs (132). Increased levels of NfL have been reported in the CSF of patients with ALS and FTD (133, 134). NfL has been suggested as a marker of FTD severity, as high concentrations in CSF are associated with shorter survival (135). A strong correlation has been observed between plasma NfL concentrations and CSF $(136,137)$, and it has been shown that serum or plasma NfL levels are increased in FTD, reflecting disease severity and predicting clinical deterioration and brain volume loss (138-141). NfL concentration only increases during the symptomatic phase, while pre-symptomatic levels are usually similar to controls (142). NfL is also a promising blood biomarker in genetic frontotemporal dementia ( GRN, C9orf72, and $M A P T)$ (143). In a longitudinal study across people from Canada and Europe with pre-symptomatic and symptomatic genetic frontotemporal dementia, NfL levels showed changes over time and correlated them with longitudinal imaging and clinical parameters. During the study, NfL levels were increased in persons who converted from pre-symptomatic, highlighting serum NfL as an easily accessible biomarker in genetic FTD dementia (143). Another study using a meta-analysis approach of fluid biomarkers to differentiate DFT from AD described that NfL were useful in distinguishing both diseases (144-146). The only report about FTD and NfL in the LAC region was done in Argentina, where 13 patients with bvFTD, 6 with lvPPA, 2 with svPPA, and 4 subjects with nfvPPA were studied. NfL levels in CSF in patients with bvFTD are higher than in MCI, AD, and controls (48), which has been described in other studies $(145,147,148)$.

\section{Progranulin}

Progranulin is a pleiotropic growth factor that is expressed in multiple tissues and cell types throughout the human body, serving important roles in normal tissue development, proliferation, regeneration, inflammation, and tumorigenesis $(149,150)$. In the brain, progranulin is involved in both neuronal survival and neurodegenerative disease $(74,151)$. Mutations in GRN cause disease through haploinsufficiency and CSF and plasma progranulin concentrations are reduced in GRN mutation carriers (152). Central nervous system progranulin levels are regulated differently from peripheral progranulin levels in neurodegenerative diseases $(134,153-157)$. This has also been observed in healthy elderly subjects (155). Peripheral levels may not adequately represent progranulin levels in the central nervous system $(155,156)$. Very low plasma progranulin levels have been observed in FTD patients with GRN mutations compared with sporadic FTD $(152,158,159)$, suggesting that this analysis is useful for detecting carriers of GRN mutations that cause haploinsufficiency (160). The only study using GRN in LAC was done in Brazil (54). Plasma progranulin were evaluated in 7 GRN mutation carriers, 55 non-carriers mutation and 60 healthy controls. Levels of plasma progranulin were significantly lower in the FTD group carriers of GRN mutations than in the FTD group without GRN mutations or in the control group. Plasma progranulin levels were also lower in the FTD without GRN mutations group, in comparison to the control group (54).

\section{TDP-43}

TDP-43 is a protein involved in alternative splicing and transcriptional regulation (161). In ALS and FTD, TDP-43 protein suffers ubiquitination, hyperphosphorylation, and also truncation of C-Terminal, increasing its aggregation profile leading to neurotoxicity and further cell death $(19,25)$. Elevated levels of TDP-43 have been observed in CSF in patients with 
ALS and FTD, with higher concentrations in ALS than in FTD, suggesting that TDP-43 is a biomarker in this disease (162). This could be explained by the higher percentage of TDP-43related pathology in ALS ( 97\%), while in FTD a significant percentage is due to other (mainly tau deposits) pathologies ( 45\%) (162). Majumder et al. conducted the first meta-analysis showing that TDP-43 in CSF is significantly increased in patients with FTD-ALS and ALS (163). However, this difference is not observed in patients with FTD alone. These data suggest the use of CSF TDP-43 as a biomarker for ALS (163). Plasma TDP43 has been useful in differentiating FTD patients with TDP43-based pathology from those with tau-based pathology (164). However, no differences in TDP-43 concentrations have been identified between patients with FTD and AD (165). By analyzing the phosphorylated form of TDP-43 (pTDP-43) which is added in the brain, they have shown a good correlation between plasma protein levels and pTDP-43 depositions in the brain (165). High concentrations of pTDP-43 in plasma were observed in C9orf72 and GRN mutation carriers, while total pTDP-43 levels were observed to be decreased (166).

All together suggest that TDP-43 may be used as a biomarker in FTD. However, at present, using our PRISMA methods we did not find studies in LAC countries and research of TDP-43 as a biomarker is still missing.

\section{A $\beta$-Amyloid, Tau, and P-Tau}

In a recent study, CSF amyloid-beta $(A \beta) 1-42$, total tau ( $\mathrm{T}$ $\mathrm{Tau}$ ), and phosphorylated tau (p-Tau) ratios, showed their clinical utility for differentiating $\mathrm{AD}$ from non-AD neurodegenerative dementias, distinguishing $\mathrm{AD}$ from both bvFTD and semantic dementia (SD, sensitivities, and specificities of $80-90 \%$ ) (167). In a similar study, low levels of the secreted form of $\mathrm{Ab}$ precursor protein (sAPPb) in CSF have been observed in patients with FTD compared to patients with $\mathrm{AD}$ and controls (168). Interestingly, the $A \beta_{42} /$ pTau181 ratio showed better differentiation between $\mathrm{AD}$ and FTD patients (169). This study was supported by two other investigations reporting increased sensitivity $(80-86 \%)$ and specificity ( $82 \%$ ) of the $A \beta_{42} /$ pTau181 ratio, suggesting that those proteins are the best biomarker subset to differentiate FTLD from $\operatorname{AD}(37,170)$. The plasma levels of p-Tau181 were significantly higher in patients on the $\mathrm{AD}$ spectrum groups and FTD patients, with the highest level in the FTD group (171). In a recent study, plasma p-tau181 distinguished AD of DFT with an AUC of $100 \%$ (172). Another phosphorylated form of tau, p-Tau217, has been studied in $\mathrm{AD}$ and other neurodegenerative diseases such as bvFTD or PPA, finding an AUC of 0.92 with a specificity of $81 \%$ and sensitivity of $93 \%$ to differentiate between these variants of FTD and AD (173). In Brazil, CSF AD biomarkers were used to distinguish a case of a frontal variant of $\mathrm{AD}$ and behavioral variant frontotemporal dementia (40). Importantly, the patient fulfilled criteria for probable bvFTD, however, CSF biomarkers signature showing low $\mathrm{A} \beta 42$, high Tau, and high p-Tau established a diagnosis of the frontal variant of $\mathrm{AD}(40)$.

\section{GFAP}

Glial fibrillary acidic protein (GFAP) is a protein widely expressed by numerous cell types of CNS, including astrocytes $(174,175)$.
GFAP, an established marker of astrogliosis in neurodegeneration $(174,175)$, have been recently described as a possible biomarker for FTD (176-179). Increased levels of GFAP have been reported in AD and ALS patients in both CSF and serum $(57,177)$. Previous studies of GFAP in FTD showed increased CSF levels in symptomatic patients, however, changes in this protein's levels in the blood have not been identified (177-179). In a recent study, GFAP concentration was analyzed in FTD patients carrying mutations in C9orf72, GRN and, MAPT in both symptomatic and pre-symptomatic subjects (176). Increased plasma levels of GFAP were only observed in GRN mutation carriers. In presymptomatic stages of the disease, elevated GFAP concentrations were correlated with lower cognitive test scores and lower brain volumes, suggesting that GFAP increases in late pre-symptomatic stages. In symptomatic stages, higher GFAP concentrations were associated with faster rates of atrophy, suggesting that GFAP could be associated with disease intensity, progression, and survival (176). In our LAC regions, no studies in GFAP levels have been performed.

\section{Inflammatory Biomarkers}

It has been suggested that immune activation may be an early cause of neurodegeneration (180) or that the addition or accumulation of tau or TDP-43 induces an increased cytotoxic response leading to chronic neuroinflammation (181-183). In FTD, the immune response is likely to be triggered by the accumulation of poorly folded tau proteins or TDP-43, or the deregulation caused by signals released by damaged neurons or the deregulation of mechanisms to remove poorly folded or damaged neuronal proteins. These processes lead to neurodegeneration $(180,184-186)$. Changes in inflammatory markers in blood, serum, and CSF have been reported in different FTD subtypes, suggesting that inflammatory factors play an important role in the pathogenesis of the disease (187). Biomarkers include some of the pro- and antiinflammatory cytokines, chemokines, and secondary messengers that coordinate the immune response through regulation of innate and adaptive responses in the periphery $(188,189)$.

Patients with genetic and sporadic FTD share similar patterns of inflammation at CSF (179). Patients with FTD show overexpression of tumor necrosis factor (TNF) and transforming growth factor (TGF-b1) in CSF, as well as microglia activation in atrophic areas of the brain $(190,191)$. One study of sporadic DFT reported elevated CSF levels of TNF- $\alpha$ (192), while another study reported decreased CSF levels of IL-12 (193). Smaller studies reported elevated CXCL8 and IL-15 levels in the CSF $(194,195)$. However, all of these findings were not reproduced in a subsequent study (196). Reports of elevated CSF levels from TGF- $\beta$ and IL-11 $(192,197)$ have not yet been reproduced or denied, while two studies have identified elevated CSF levels from CCL2 in sporadic FTD $(194,196)$. Progranulin appears to be involved in neuroinflammation and microglia activation (198-200). In a small cohort of GRN mutation carriers, an apparent CSF profile of elevated CXCL10 and decreased levels of TNF- $\alpha$, IL-15, and CCL5 have been described (196). Another recently identified marker of neuroinflammation is soluble TREM2. TREM2 encodes a receptor expressed on immune cells 
that regulate phagocytosis. In the brain, TREM2 is expressed exclusively by microglia (201), and it has been suggested that TREM2 levels are a marker of microglia and neuroinflammation activity (202). In carriers of TREM2 mutations, sTREM2 CSF levels are decreased, suggesting a loss of function as a pathological mechanism (203). One study also found that CSF sTREM2 levels decreased in a larger cohort of patients with FTD, including carriers with C9orf72 and GRN mutations (204).

Studies of circulating inflammatory biomarkers in patients with FTD are scarce even though blood samples are easier to obtain than CSF and also, the results have been inconsistent. One study shows that IL-6 levels are increased in FTD patients carrying GRN mutations when compared to pre-symptomatic carriers, suggesting an inflammatory response when FTD symptoms appear (205). In a cross-sectional study of patients with a mutation in the gene $C H M P 2 B$ associated frontotemporal dementia, levels of inflammatory markers such as CCL4 IL15, CXCL10, CCL22, and TNF- $\alpha$ were found increased and significantly associated with cognitive decline, suggesting a peripheral inflammatory response to neurodegeneration (206). In Brazil, Fraga et al. for the first time evaluated different proteins involved in the immune response in patients with FTD (43). The proteins evaluated in plasma were high sensitivity $C$ reactive protein (hsCRP), TNF, IL- $\beta 1$, IL- 6 , TGF- $\beta 1$, LXA4, and AnxA1, and investigated changes in LXA4 e AnxA1 levels in CSF bvFTD patients. For AnxA1 alone, a reduction in plasma levels was demonstrated in bvFTD patients compared to AD and controls. However, no difference was observed between $\mathrm{AD}$ and bvFTD in CSF (43). Another study performed in Brazil analyzed a B7-CD28/CTLA-4 pathway that is an important immunological signaling pathway involved in the modulation of $\mathrm{T}$ cell activation. Forty-six patients were included in this study divided into three groups: $27 \mathrm{AD}, 10 \mathrm{FTD}$, and 9 control patients. The FTD group was composed of 7 patients with bvFTD, 2 patients with progressive non-fluent aphasia, and 1 patient with semantic dementia. CTLA-4 expression showed a reduction in FTD patients compared to AD or control groups (R. R. 205).

\section{Proteomics and Metabolomics}

Unbiased mass spectrometry (MS) was performed and identified 20 differentially abundant proteins between symptomatic GRN mutation carriers and 24 non-carriers and 9 between 19 symptomatic and 9 pre-symptomatic mutation carriers. These results were validated in subjects symptomatic and presymptomatic mutation carriers of C9orf72 and MAPT, in addition to GRN carriers (143). A validation study performed by targeted mass spectrometry showed significantly lower levels of NPTXR, CHGA, VSTM2B, PTPRN2, and VGF in symptomatic GRN mutation carriers compared to pre-symptomatic and noncarriers. Four of the 5 protein decreases (NPTXR, VSTM2B, CHGA, and PTPRN2) were observed in symptomatic GRN carriers as well as symptomatic C9orf72 carriers, suggesting that these changes are not specific for GRN associated FTD. In MAPT mutation carriers, significant differences in protein concentrations were only found for NPTXR and CHGA. This suggests that may there be differences in pathophysiology in MAPT mutation carriers or it may be due to the smaller sample size (143). The results show that synaptic, secretory vesicle, and inflammatory proteins are dysregulated in the symptomatic stage in mutation carriers and may provide new insights into the pathophysiology of genetic FTD (143). One study performed in Brazil using gas chromatography coupled to mass spectrometry (GC-MS) included nine patients with bvFTD, 17 with AD and 15 cognitively healthy controls in the training set, whose data were validated on a testing set of 8 bvFTD, $14 \mathrm{AD}$, and 10 controls (52). Differences were identified when compared to the bvFTD and control groups, but not between bvFTD and AD groups. The bvFTD group showed decreased levels of plasma of metabolites related to glycine/serine/threonine, alanine/aspartate/glutamate pathways, and aminoacyl-tRNA biosynthesis when compared to controls. These results suggest that impairment of amino acid metabolism and the translation process may be present in bvFTD patients (52).

\section{CONCLUSIONS AND FUTURE DIRECTIONS}

FTD, like the rest of dementias, is a public health problem, often underdiagnosed, undertreated, and not fully understood. This situation is especially relevant in LAC, presenting several barriers to diagnosis, treatment, and further research on FTD. In this review, we showed local efforts to make research on biomarkers in the LAC region. Until today most of the knowledge about FTD comes from North America and Europe cohorts, providing guidelines and descriptions that do not necessarily capture the local reality in terms of psychopathology, genetics, or diagnostic tools. Aligned with that, our current analysis in this systematic review revealed only 21 articles published between January 2000 until November 2020 in LAC, considering FTD participants and genetic, neuroimaging, or fluid biomarkers studies (Table 1). Interestingly, most of the researchers are coming from Argentina, and Brazil, representing more than $55 \%$ of all of the manuscripts (Table 2). Most of the literature comes from genetics and neuroimaging studies, representing $\sim 70 \%$ of the articles. As we showed in Figure 2, the C9orf 72 gene is widely represented in familial and sporadic cases from Chile, Brazil and Argentina, followed by MAPT and GRN genes, as described in HIC. Several neuroimaging techniques are being used, however, most of the LAC research described in our review is based on structural neuroimaging, functional imaging, and EEG. In this context, further research is needed to expand these biomarkers across LAC, allowing a better and accurate diagnosis.

Important to emphasize, studies on fluid biomarkers also proceeded exclusively from Brazil and Argentina (37, 40, 43, 48, $51,52)$. Nfl, PGNR, and TDP-43 proteins appear to be the best molecules for FTD diagnosis in most of the studies. However, no studies of TDP-43 in the LAC region have been performed to distinguish controls from dementia patients, making it clear that it is imperative to develop and study fluid biomarkers in our regions. Despite the contribution of LAC studies, our review suggests that biomarkers research is still needed to increase the comprehension knowledge about FTD pathology in LAC and 
TABLE 2 | Quantity distribution of papers.

\begin{tabular}{|c|c|c|c|c|c|c|c|c|c|}
\hline \multirow[t]{2}{*}{ Papers } & \multicolumn{6}{|c|}{ Country } & \multicolumn{3}{|c|}{ Category } \\
\hline & Argentina & Brazil & Colombia & Chile & Australia & France & Genetics & Neuroimaging & Fluid biomarkers \\
\hline Quantity/Percentage (\%) & $12 / 35.3$ & $7 / 20.6$ & $7 / 20.6$ & $5 / 14.7$ & $2 / 5.9$ & $1 / 2.9$ & $7 / 30.4$ & $10 / 43.5$ & $6 / 26.1$ \\
\hline
\end{tabular}

Quantity and percentage of papers by country and category for the data analysis.

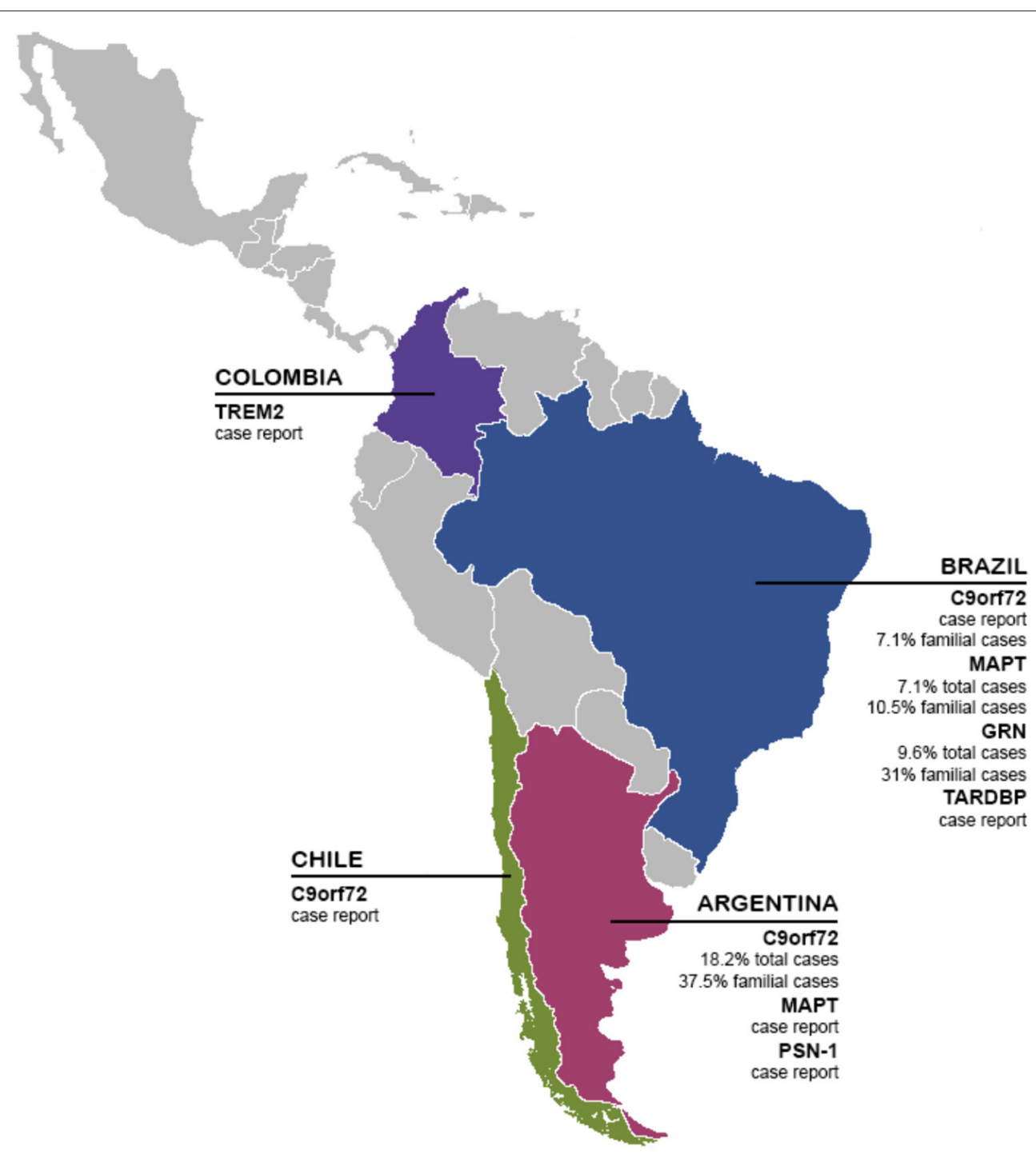

FIGURE 2 | Genetics biomarkers of FTD in LAC. The presence and frequency of FTD genetic biomarkers (TREM2, C9orf72, MAPT, GRN, TARDBP, and PSN-1) in LAC.

their contribution to clinical diagnosis. Biomarkers research is yet limited in number with a small sample size or simply case reports. In a recent study, plasma p-tau181 distinguished $\mathrm{AD}$ of DFT with an AUC of $100 \%$ (172), suggesting that this protein could be used as a potential diagnosis tool, however no studies of this protein has been developed in the LAC region.
Knowledge of the clinical manifestation of FTD has progressed exponentially over the past 20 years (19). However, the heterogeneity of the clinical outcome of FTD together with the potential overlapping with other conditions leads to considerable misdiagnosis by clinicians (19). In context, clinicians, biomedical, and basic researchers have increased 
awareness about this disabling neurodegenerative condition, especially in vulnerable regions such as LAC. Moreover, considering the mixed genetic heritage of LAC and the high prevalence of cardiovascular risk (207), among others, we highlight the need to develop strategies to increase research in the region to study the contribution of biomarkers, mainly fluid biomarkers, to understand the pathology of FTD and improve diagnosis.

Recent years have seen a rapid development of biomarkers for FTD and other dementias (29-31). LAC region is experiencing increased demand for harmonized, innovative, and crossregional studies on dementias, including FTD. Across the LAC countries, the case of FTD is even more challenging than AD. LAC region may be driven by unique genetic factors which could influence the prevalence and presentation of dementia (1-3, 208-213). However, region-specific determinants remain unknown and the region is still underrepresented in international publications/journals including studies in prevalence, social determinants, and local research of genetics and biomarkers $(2,3)$. Thus, specific knowledge on the regional reality of LAC is still scarce and limited $(2,3,214)$. It is important to mention that the most frequent limitations raised by researchers are the lack of infrastructure, technology, availability of samples from native populations specific to each LAC country, and the high costs associated with biomarker analysis (3).

Recently, multiple regional research efforts have been developed in LAC countries focused on the use of machine learning for the combination of neuroimaging modalities as well as behavioral/cognitive assessment to a better understanding of different dementias in our region $(36,130,215-219)$. A multifeature framework, targeting no one single potential biomarker, but a multilevel combination of measures, tuned by machine learning algorithms robust to assess simultaneously multiple features, supporting redundancy of information, and extracting the main components via progressive feature elimination process, would represent a new-generation promissory approach to target the complex multimodal nature of FTD. Dementia research in the region is certainly reduced in comparison with HIC in the LAC, highlighting an urgent need to integrate different areas of

\section{REFERENCES}

1. Baez S, Ibáñez A. Dementia in Latin America: an emergent silent tsunami. In Front Aging Neurosci. (2016) 8:253. doi: 10.3389/fnagi.2016.00253

2. Parra MA, Baez S, Allegri R, Nitrini R, Lopera F, Slachevsky A, et al. Dementia in Latin America assessing the present and envisioning the future. Neurology. (2018) 90:222-31. doi: 10.1212/WNL.0000000000004897

3. Parra MA, Baez S, Sedeño L, Gonzalez Campo C, Santamaría-García $\mathrm{H}$, Aprahamian I, et al. Dementia in Latin America: paving the way toward a regional action plan. Alzheimers Dement. (2020) 17:295313. doi: $10.1002 /$ alz.12202

4. Lancet Neurology. A neurology revival in Latin America. Lancet Neurol. (2015) 14:1143. doi: 10.1016/S1474-4422(15)00307-5

5. Manes F. The huge burden of dementia in Latin America. Lancet Neurol. (2016) 15:29. doi: 10.1016/S1474-4422(15)00360-9

6. Custodio N, Wheelock A, Thumala D, Slachevsky A. Dementia in Latin America: epidemiological evidence and implications for public policy. Front Aging Neurosci. (2017) 9:221. doi: 10.3389/fnagi.2017.00221 dementia knowledge with a more global perspective $(6,209)$. Thus, the development of a more extended regional network establishing multi-center LAC initiatives is critical for global discovery and research standardization of dementia in these underrepresented cohorts.

\section{DATA AVAILABILITY STATEMENT}

The raw data supporting the conclusions of this article will be made available by the authors, without undue reservation.

\section{AUTHOR CONTRIBUTIONS}

CD-A and AS designed the proposal. $\mathrm{PO}$ and MA-P performed PRISMA analysis. CD-A, PO, TL, FH, VC, TE, MP, and AS wrote the drafts, discussed contributions from all co-authors. All authors searched the literature, participated in discussing the contents of the paper, contributed to editing, and approved the final version of the article.

\section{FUNDING}

This work was funded by the Alzheimer Disease Association 2018-AARG-591107, ANID/FONDEF ID20I10152, and ANID/FONDECYT 1210622 to CD-A. AI is supported by Alzheimer's Association GBHI ALZ UK-20-639295, Takeda CW2680521, Sistema General de Regalías [BPIN2018000100059], and the Multi-Partner Consortium to Expand Dementia Research in Latin America [ReDLat, supported by National Institutes of Health, National Institutes of Aging (R01 AG057234), Alzheimer's Association (SG-20725707), Tau Consortium, and Global Brain Health Institute]. AS was supported by grants from ANID/FONDAP/15150012, ANID/FONDEF/ID 18I10113, ANID/Fondecyt/1191726, MultiPartner Consortium to Expand Dementia Research in Latin America [ReDLat, supported by National Institutes of Health, National Institutes of Aging (R01 AG057234), Alzheimer's Association (SG-20-725707), Tau Consortium, and Global Brain Health Institute].
7. Mansfield E, Noble N, Sanson-Fisher R, Mazza D, Bryant J, Heyn PC. Primary care physicians' perceived barriers to optimal dementia care: a systematic review. Gerontologist. (2019) 59:E697-708. doi: 10.1093/geront/gny067

8. Olavarría L, Mardones C, Delgado C, Andrea SC. chilean healthcare professionals' perception of knowledge about dementia. Rev Med Chile. (2016) 144:1365-68. doi: 10.4067/S0034-98872016001000019

9. Saxena S, Thornicroft G, Knapp M, Whiteford H. Resources for mental health: scarcity, inequity, and inefficiency. Lancet. (2007) 370:87889. doi: 10.1016/S0140-6736(07)61239-2

10. Alzheimer's Disease International, and World Health Organization. Dementia a Public Health Priority. Washington, DC: WHO (2012).

11. Custodio N, Herrera-Perez E, Lira D, Montesinos R, Bendezu L. Prevalence of frontotemporal dementia in community-based studies in Latin America: a systematic review. Dement Neuropsychol. (2013) 7:2732. doi: 10.1590/S1980-57642013DN70100005

12. Nitrini R, Bottino CMC, Albala C, Custodio Capunay NS, Ketzoian C, Llibre Rodriguez JJ, et al. Prevalence of dementia in Latin America: a 
collaborative study of population-based cohorts. Int Psychogeriatr. (2009) 21:622-30. doi: 10.1017/S1041610209009430

13. Nitrini R, Barbosa MT, Brucki SMD, Yassuda MS, Caramelli P. Current trends and challenges on dementia management and research in Latin America. J Glob Health. (2020) 10:010362. doi: 10.7189/jogh.10.010362

14. Hodges JR, Davies R, Xuereb J, Kril J, Halliday G. Survival in frontotemporal dementia. Neurology. (2003) 61:34954. doi: 10.1212/01.WNL.0000078928.20107.52

15. Knopman DS, Roberts RO. Estimating the number of persons with frontotemporal lobar degeneration in the US population. J Mol Neurosci. (2011) 45:330-5. doi: 10.1007/s12031-011-9538-y

16. Bang J, Spina S, Miller BL. Frontotemporal dementia. Lancet. (2015) 386:1672-82. doi: 10.1016/S0140-6736(15)00461-4

17. Vieira RT. Epidemiology of early-onset dementia: a review of the literature. Clin Pract Epidemiology Ment Health. (2013) 9:88-95. doi: 10.2174/1745017901309010088

18. Deleon J, Miller BL. Frontotemporal dementia. Handb Clin Neurol. (2018) 148:409-30. doi: 10.1016/B978-0-444-64076-5.00027-2

19. Olney NT, Spina S, Miller BL. Frontotemporal dementia. Neurol Clin. (2017) 35:339-74. doi: 10.1016/j.ncl.2017.01.008

20. Lanata SC, Miller BL. The behavioural variant frontotemporal dementia (bvFTD) syndrome in psychiatry. J Neurol Neurosurg Psychiatry. (2016) 87:501-11. doi: 10.1136/jnnp-2015-310697

21. Lopez OL, Litvan I, Catt KE, Stowe R, Klunk W, Kaufer DI, et al. Accuracy of four clinical diagnostic criteria for the diagnosis of neurodegenerative dementias. Neurology. (1999) 53:1292-9. doi: 10.1212/WNL.53.6.1292

22. Snowden JS, Neary D, Mann DMA. Frontotemporal dementia. $\mathrm{Br} J$ Psychiatry. (2002) 180:140-3. doi: 10.1192/bjp.180.2.140

23. Guimarães HC, Vale TC, Pimentel V, de Sá NC, Beato RG, Caramelli P. Analysis of a case series of behavioral variant frontotemporal dementia: emphasis on diagnostic delay. Dement Neuropsychol. (2013) 7:559. doi: 10.1590/S1980-57642013DN70100009

24. Rasmussen H, Hellzen O, Stordal E, Enmarker I. Family caregivers experiences of the pre-diagnostic stage in frontotemporal dementia. Geriatr Nurs. (2019) 40:246-51. doi: 10.1016/j.gerinurse.2018.10.006

25. Solomon DA, Mitchell JC, Salcher-Konrad MT, Vance CA, Mizielinska S. Review: Modelling the pathology and behaviour of frontotemporal dementia. Neuropathol Appl Neurobiol. (2019) 45:58-80. doi: 10.1111/nan.12536

26. Rohrer JD, Guerreiro R, Vandrovcova J, Uphill J, Reiman D, Beck J, et al. The heritability and genetics of frontotemporal lobar degeneration. Neurology. (2009) 73:1451-6. doi: 10.1212/WNL.0b013e3181bf997a

27. Rosso SM, Kaat LD, Baks T, Joosse M, De Koning I, Pijnenburg Y, et al. Frontotemporal dementia in the Netherlands: patient characteristics and prevalence estimates from a population-based study. Brain. (2003) 126:201622. doi: 10.1093/brain/awg204

28. Atkinson AJ, Colburn WA, DeGruttola VG, DeMets DL, Downing GJ, Hoth DF, et al. Biomarkers and surrogate endpoints: preferred definitions and conceptual framework. Clin Pharmacol Therapeut. (2001) 69:8995. doi: $10.1067 / \mathrm{mcp} .2001 .113989$

29. Convery R, Mead S, Rohrer JD. Review: clinical, genetic and neuroimaging features of frontotemporal dementia. Neuropathol Appl Neurobiol. (2019) 45:6-18. doi: 10.1111/nan. 12535

30. Meeter LH, Kaat LD, Rohrer JD, Van Swieten JC. Imaging and fluid biomarkers in frontotemporal dementia. Nat Rev Neurol. (2017) 13:40619. doi: 10.1038/nrneurol.2017.75

31. Zetterberg H, van Swieten JC, Boxer AL, Rohrer JD. Review: fluid biomarkers for frontotemporal dementias. Neuropathol Appl Neurobiol. (2019) 45:817. doi: $10.1111 /$ nan. 12530

32. Ahmed Z, Cooper J, Murray TK, Garn K, McNaughton E, Clarke $\mathrm{H}$, et al. A novel in vivo model of tau propagation with rapid and progressive neurofibrillary tangle pathology: the pattern of spread is determined by connectivity, not proximity. Acta Neuropathol. (2014) 127:667-83. doi: 10.1007/s00401-014-1254-6

33. Liberati A, Altman DG, Tetzlaff J, Mulrow C, Gøtzsche PC, Ioannidis JPA, et al. The PRISMA statement for reporting systematic reviews and metaanalyses of studies that evaluate healthcare interventions: explanation and elaboration. BMJ. (2009) 339:b2700. doi: 10.1136/bmj.b2700
34. Baez S, Morales JP, Slachevsky A, Torralva T, Matus C, Manes F, et al. Orbitofrontal and limbic signatures of empathic concern and intentional harm in the behavioral variant frontotemporal dementia. Cortex. (2016) 75:20-32. doi: 10.1016/j.cortex.2015.11.007

35. Baez S, Kanske P, Matallana D, Montanes P, Reyes P, Slachevsky A, et al. Integration of intention and outcome for moral judgment in frontotemporal dementia: brain structural signatures. Neurodegener Dis. (2016) 16:20617. doi: $10.1159 / 000441918$

36. Bachli MB, Sedeño L, Ochab JK, Piguet O, Kumfor F, Reyes $\mathrm{P}$, et al. Evaluating the reliability of neurocognitive biomarkers of neurodegenerative diseases across countries: a machine learning approach. NeuroImage. (2020) 208:116456. doi: 10.1016/j.neuroimage.2019.116456

37. Baldeiras I, Santana I, Leitão MJ, Ribeiro MH, Pascoal R, Duro D, et al. Cerebrospinal fluid $A \beta 40$ is similarly reduced in patients with frontotemporal lobar degeneration and alzheimer's disease. J Neurol Sci. (2015) 358:308-16. doi: 10.1016/j.jns.2015.09.022

38. Bertoux M, Flanagan EC, Hobbs M, Ruiz-Tagle A, Delgado C, Miranda $\mathrm{M}$, et al. Structural anatomical investigation of long-term memory deficit in behavioral frontotemporal dementia. J Alzheimers Dis. (2018) 62:1887900. doi: 10.3233/JAD-170771

39. Cintra VP, Bonadia LC, Andrade HMT, de Albuquerque M, Eusébio MF, de Oliveira DS, et al. The frequency of the C9orf72 expansion in a Brazilian population. Neurobiol Aging. (2018) 66:179.e1-4. doi: 10.1016/j.neurobiolaging.2018.01.007

40. De Souza LC, Mariano LI, De Moraes RF, Caramelli P. Behavioral variant of frontotemporal dementia or frontal variant of alzheimer's disease? Dement Neuropsychol. (2019) 13:356-60. doi: 10.1590/1980-57642018dn13-030015

41. Dottori M, Seden,õ L, Martorell Caro M, Alifano F, Hesse E, Mikulan E, et al. Towards affordable biomarkers of frontotemporal dementia: a classification study via network's information sharing. Sci Rep. (2017) 7:3822. doi: 10.1038/s41598-017-04204-8

42. Fernández Suarez M, Surace E, Harris P, Tapajoz F, Sevlever G, Allegri R, et al. C9ORF72 G4C2-repeat expansion and frontotemporal dementia first reported case in Argentina. Neurocase. (2016) 22:2814. doi: 10.1080/13554794.2016.1186700

43. Fraga VG, Magalhães CA, Loures C, de MG, de Souza LC, Guimarães HC, et al. Inflammatory and pro-resolving mediators in frontotemporal dementia and alzheimer's disease. Neuroscience. (2019) 421:123-35. doi: 10.1016/j.neuroscience.2019.09.008

44. Gatto EM, Allegri RF, Da Prat G, Chrem Mendez P, Hanna DS, Dorschner MO, et al. Intrafamilial variable phenotype including corticobasal syndrome in a family with p.P301L mutation in the MAPT gene: first report in South America. Neurobiol Aging. (2017) 53:195.e117. doi: 10.1016/j.neurobiolaging.2017.02.002

45. Itzcovich T, Xi Z, Martinetto H, Chrem-Méndez P, Russo MJ, de Ambrosi $\mathrm{B}$, et al. Analysis of C9orf72 in patients with frontotemporal dementia and amyotrophic lateral sclerosis from Argentina. Neurobiol Aging. (2016) 40:192.e13-5. doi: 10.1016/j.neurobiolaging.2016.02.001

46. Miranda CM, Bustamante CML, Herrera CL. Abnormal expansion of C9orf72 gene in familial frontotemporal dementia. Rev Med Chile. (2017) 145:896-900. doi: 10.4067/s0034-98872017000700896

47. Moguilner S, García AM, Mikulan E, Hesse E, García-Cordero I, Melloni M, et al. Weighted symbolic dependence metric (wSDM) for fMRI resting-state connectivity: a multicentric validation for frontotemporal dementia. Sci Rep. (2018) 8:11181. doi: 10.1038/s41598-018-29538-9

48. Niikado M, Chrem-Méndez P, Itzcovich T, Barbieri-Kennedy M, Calandri I, Martinetto $\mathrm{H}$, et al. Evaluation of cerebrospinal fluid neurofilament light chain as a routine biomarker in a memory clinic. J Gerontol Ser A Biol Sci Med Sci. (2019) 74:442-5. doi: 10.1093/gerona/gly179

49. Riudavets MA, Bartoloni L, Troncoso JC, Pletnikova O, St. GeorgeHyslop P, Schultz M, et al. Familial dementia with frontotemporal features associated with M146V presenilin-1 mutation. Brain Pathol. (2013) 23:595600. doi: 10.1111/bpa.12051

50. Santamaria-Garcia H, Reyes P, Garcia A, Baez S, Martinez A, Santacruz JM, et al. First symptoms and neurocognitive correlates of behavioral variant frontotemporal dementia. J Alzheimers Dis. (2016) 54:95770. doi: 10.3233/JAD-160501 
51. Santos RR, Torres KC, Lima GS, Fiamoncini CM, Mapa FC, Pereira PA, et al. Reduced frequency of T lymphocytes expressing CTLA- 4 in frontotemporal dementia compared to alzheimer's disease. Progr Neuro Psychopharmacol Biol Psychiatry. (2014) 48:1-5. doi: 10.1016/j.pnpbp.2013.06.019

52. Santos ALM, Vitório JG, de Paiva MJN, Porto BLS, Guimarães HC, Canuto $\mathrm{GAB}$, et al. Frontotemporal dementia: plasma metabolomic signature using gas chromatography-mass spectrometry. J Pharmaceut Biomed Anal. (2020) 189:113424. doi: 10.1016/j.jpba.2020.113424

53. Sedeño L, Piguet O, Abrevaya S, Desmaras H, Garcia-Cordero I, Baez S, et al. Tackling variability: a multicenter study to provide a gold-standard network approach for frontotemporal dementia. Hum Brain Mapp. (2017) 38:3804-22. doi: 10.1002/hbm.23627

54. Takada LT, Bahia VS, Guimarães HC, Costa TV, Vale TC, Rodriguez $\mathrm{RD}$, et al. GRN and MAPT mutations in 2 frontotemporal dementia research centers in Brazil. Alzheimer Dis Assoc Disord. (2016) 30:3107. doi: $10.1097 / \mathrm{WAD} .0000000000000153$

55. Gossye H, Van Broeckhoven C, Engelborghs S. The use of biomarkers and genetic screening to diagnose frontotemporal dementia: evidence and clinical implications. Front Genet. (2019) 10:757. doi: 10.3389/fnins.2019.00757

56. Miller B, Llibre Guerra JJ. Frontotemporal dementia. Handb Clin Neurol. (2019) 165:33-45. doi: 10.1016/B978-0-444-64012-3.00003-4

57. Lewczuk P, Riederer P, O’Bryant SE, Verbeek MM, Dubois B, Visser PJ, et al. Cerebrospinal fluid and blood biomarkers for neurodegenerative dementias: an update of the consensus of the task force on biological markers in psychiatry of the world federation of societies of biological psychiatry. World J Biol Psychiatry. (2018) 19:244-328. doi: 10.1080/15622975.2017.1375556

58. Piguet O, Hodges JR. Behavioural-variant frontotemporal dementia: an update. Dement Neuropsychol. (2013) 7:1018. doi: 10.1590/S1980-57642013DN70100003

59. Lashley T, Rohrer JD, Mead S, Revesz T. Review: an update on clinical, genetic and pathological aspects of frontotemporal lobar degenerations. Neuropathol Appl Neurobiol. (2015) 41:858-81. doi: 10.1111/nan. 12250

60. DeJesus-Hernandez M, Mackenzie IR, Boeve BF, Boxer AL, Baker M, Rutherford NJ, et al. Expanded GGGGCC hexanucleotide repeat in noncoding region of C9ORF72 causes chromosome 9p-linked FTD and ALS. Neuron. (2011) 72:245-56. doi: 10.1016/j.neuron.2011.09.011

61. Hodges J. Familial frontotemporal dementia and amyotrophic lateral sclerosis associated with the C9ORF72 hexanucleotide repeat. Brain. (2012) 135:652-5. doi: 10.1093/brain/aws033

62. Renton AE, Majounie E, Waite A, Simón-Sánchez J, Rollinson S, Gibbs JR, et al. A hexanucleotide repeat expansion in C9ORF72 is the cause of chromosome 9p21-linked ALS-FTD. Neuron. (2011) 72:25768. doi: 10.1016/j.neuron.2011.09.010

63. Greaves CV, Rohrer JD. An update on genetic frontotemporal dementia. J Neurol. (2019) 266:2075-86. doi: 10.1007/s00415-019-09363-4

64. Majounie E, Renton AE, Mok K, Dopper EGP, Waite A, Rollinson S, et al. Frequency of the C9orf72 hexanucleotide repeat expansion in patients with amyotrophic lateral sclerosis and frontotemporal dementia: a cross-sectional study. Lancet Neurol. (2012) 11:323-30. doi: 10.1016/S1474-4422(12)70043-1

65. Jang JH, Kwon MJ, Choi WJ, Oh KW, Koh SH, Ki CS, et al. Analysis of the C9orf72 hexanucleotide repeat expansion in Korean patients with familial and sporadic amyotrophic lateral sclerosis. Neurobiol Aging. (2013) 34:1311.e7-9. doi: 10.1016/j.neurobiolaging.2012.09.004

66. Ogaki K, Li Y, Atsuta N, Tomiyama H, Funayama M, Watanabe H, et al. Analysis of C9orf72 repeat expansion in 563 Japanese patients with amyotrophic lateral sclerosis. Neurobiol Aging. (2012) 33:2527.e116. doi: 10.1016/j.neurobiolaging.2012.05.011

67. Alavi A, Nafissi S, Rohani M, Shahidi G, Zamani B, Shamshiri H, et al. Repeat expansion in C9ORF72 is not a major cause of amyotrophic lateral sclerosis among iranian patients. Neurobiol Aging. (2014) 35:267.e17. doi: 10.1016/j.neurobiolaging.2013.07.016

68. Takada LT, Pimentel MLV, DeJesus-Hernandez M, Fong JC, Yokoyama JS, Karydas A, et al. Frontotemporal dementia in a Brazilian kindred with the C9orf72 mutation. Arch Neurol. (2012) 69:1149-53. doi: 10.1001/archneurol.2012.650
69. Strang KH, Golde TE, Giasson BI. MAPT mutations, tauopathy, and mechanisms of neurodegeneration. Lab Invest. (2019) 99:912-28. doi: 10.1038/s41374-019-0197-x

70. Beck J, Rohrer JD, Campbell T, Isaacs A, Morrison KE, Goodall EF, et al. A distinct clinical, neuropsychological and radiological phenotype is associated with progranulin gene mutations in a large UK series. Brain. (2008) 131:70620. doi: 10.1093/brain/awm 320

71. Le Ber I, Camuzat A, Guillot-Noel L, Hannequin D, Lacomblez L, Golfier V, et al. C9ORF72 repeat expansions in the frontotemporal dementias spectrum of diseases: a flow-chart for genetic testing. J Alzheimers Dis. (2013) 34:48599. doi: 10.3233/JAD-121456

72. Das G, Sadhukhan T, Sadhukhan D, Biswas A, Pal S, Ghosh A, et al. Genetic study on frontotemporal lobar degeneration in India. Parkinsonism Relat Disord. (2013) 19:487-9. doi: 10.1016/j.parkreldis.2012.11.015

73. Kim EJ, Kwon JC, Park KH, Park KW, Lee JH, Choi SH, et al. Clinical and genetic analysis of MAPT, GRN, and C9orf72 genes in Korean patients with frontotemporal dementia. Neurobiol Aging. (2014) 35:1213.e137. doi: 10.1016/j.neurobiolaging.2013.11.033

74. Petkau TL, Leavitt BR. Progranulin in neurodegenerative disease. Trends Neurosci. (2014) 37:388-98. doi: 10.1016/j.tins.2014.04.003

75. Benussi L, Ghidoni R, Binetti G. Progranulin mutations are a common cause of FTLD in northern Italy. Alzheimer Dis Assoc Disord. (2010) 24:3089. doi: 10.1097/WAD.0b013e3181d1bb13

76. Chiang HH, Forsell C, Lilius L, Öijerstedt L, Thordardottir S, Shanmugarajan $\mathrm{K}$, et al. Novel progranulin mutations with reduced serum-progranulin levels in frontotemporal lobar degeneration. Euro J Hum Genet. (2013) 21:1260-5. doi: 10.1038/ejhg.2013.37

77. Seelaar H, Kamphorst W, Rosso SM, Azmani A, Masdjedi R, De Koning I, et al. Distinct genetic forms of frontotemporal dementia. Neurology. (2008) 71:1220-6. doi: 10.1212/01.wnl.0000319702.37497.72

78. Van Langenhove T, van der Zee J, Gijselinck I, Engelborghs S, Vandenberghe $\mathrm{R}$, Vandenbulcke $\mathrm{M}$, et al. Distinct clinical characteristics of C9orf72 expansion carriers compared with GRN, MAPT, and nonmutation carriers in a Flanders-Belgian FTLD cohort. JAMA Neurol. (2013) 70:36573. doi: 10.1001/2013.jamaneurol.181

79. Ogaki K, Li Y, Takanashi M, Ishikawa KI, Kobayashi T, Nonaka T, et al. Analyses of the MAPT, PGRN, and C9orf72 mutations in Japanese patients with FTLD, PSP, CBS. Parkinsonism Relat Disord. (2013) 19:1520. doi: 10.1016/j.parkreldis.2012.06.019

80. Buratti E, De Conti L, Stuani C, Romano M, Baralle M, Baralle F. Nuclear factor TDP-43 can affect selected microRNA levels. FEBS J. (2010) 277:226881. doi: $10.1111 /$ j.1742-4658.2010.07643.x

81. Polymenidou M, Lagier-Tourenne C, Hutt KR, Huelga SC, Moran J, Liang $\mathrm{TY}$, et al. Long pre-mRNA depletion and RNA missplicing contribute to neuronal vulnerability from loss of TDP-43. Nat Neurosci. (2011) 14:45968. doi: 10.1038/nn.2779

82. Tollervey JR, Curk T, Rogelj B, Briese M, Cereda M, Kayikci M, et al. Characterizing the RNA targets and position-dependent splicing regulation by TDP-43. Nat Neurosci. (2011) 14:452-8. doi: 10.1038/nn.2778

83. Banks GT, Kuta A, Isaacs AM, Fisher EMC. TDP-43 is a culprit in human neurodegeneration, and not just an innocent bystander. Mamm Genome. (2008) 19:299-305. doi: 10.1007/s00335-008-9117-x

84. Barmada SJ, Finkbeiner S. Pathogenic TARDBP mutations in amyotrophic lateral sclerosis and frontotemporal dementia: disease-associated pathways. Rev Neurosci. (2010) 21:251-72. doi: 10.1515/REVNEURO.2010. 21.4.251

85. Gendron TF, Rademakers R, Petrucelli L. TARDBP mutation analysis in TDP-43 proteinopathies and deciphering the toxicity of mutant TDP-43. $J$ Alzheimers Dis. (2013) 33 (Suppl. 1):S43-5. doi: 10.3233/JAD-2012-129036

86. Pesiridis GS, Lee VMY, Trojanowski JQ. Mutations in TDP-43 link glycinerich domain functions to amyotrophic lateral sclerosis. Hum Mol Genet. (2009) 18:R156-62. doi: 10.1093/hmg/ddp303

87. Lattante S, Rouleau GA, Kabashi E. TARDBP and FUS mutations associated with amyotrophic lateral sclerosis: summary and update. Hum Mutat. (2013) 34:e1-6. doi: 10.1002/humu.22319

88. Costa, T. V. M. M. Analysis of the Presence of Mutation in TARDBP Gene in Patients With Frontotemporal Lobar Degeneration and Implementation of APOE Gene Methodology for Polymorphism Determination in Patients With 
Alzheimer's Disease in São Paulo. Biblioteca Digital de Teses e Dissertações da Universidade de São Paulo. São Paulo (2012).

89. George-Hyslop PS, Haines J, Rogaev E, Mortilla M, Vaula G, Pericak-Vance $\mathrm{M}$, et al. Genetic evidence for a novel familial Alzheimer's disease locus on chromosome 14. Nat Genet. (1992) 2:330-4. doi: 10.1038/ng1292-330

90. Rogaeva EA, Fafel KC, Song YQ, Medeiros H, Sato C, Liang Y, et al. Screening for PS1 mutations in a referral-based series of AD cases: 21 novel mutations. Neurology. (2001) 57:621-5. doi: 10.1212/WNL.57.4.621

91. Hutton M. Presenilin mutations associated with fronto-temporal dementia. Ann Neurol. (2004) 55:604-6. doi: 10.1002/ana.20103

92. Dermaut B, Kumar-Singh S, Engelborghs S, Theuns J, Rademakers R, Saerens J, et al. A novel presenilin 1 mutation associated with pick's disease but not $\beta$-amyloid plaques. Ann Neurol. (2004) 55:617-26. doi: 10.1002/ana.20083

93. Guerreiro R, Bilgic B, Guven G, Brás J, Rohrer J, Lohmann E, et al. A novel compound heterozygous mutation in TREM2 found in a Turkish frontotemporal dementia-like family. Neurobiol Aging. (2013) 34:15. doi: 10.1016/j.neurobiolaging.2013.06.005

94. Paloneva J, Autti T, Raininko R, Partanen J, Salonen O, Puranen M, et al. CNS manifestations of nasu-hakola disease: a frontal dementia with bone cysts. Neurology. (2001) 56:1552-8. doi: 10.1212/WNL.56.11.1552

95. Guerreiro RJ, Lohmann E, Brás JM, Gibbs JR, Rohrer JD, Gurunlian N, et al. Using exome sequencing to reveal mutations in TREM2 presenting as a frontotemporal dementia-like syndrome without bone involvement. JAMA Neurol. (2013) 70:78-84. doi: 10.1001/jamaneurol.2013.579

96. Le Ber I, De Septenville A, Guerreiro R, Bras J, Camuzat A, Caroppo $\mathrm{P}$, et al. Homozygous TREM2 mutation in a family with atypical frontotemporal dementia. Neurobiol Aging. (2014) 35:2419.e23-5. doi: 10.1016/j.neurobiolaging.2014.04.010

97. Chouery E, Delague V, Bergougnoux A, Koussa S, Serre, J.-L., et al. Mutations in TREM2 lead to pure early-onset dementia without bone cysts. Hum Mutat. (2008) 29:E194-204. doi: 10.1002/humu.20836

98. Ng ASL, Tan YJ, Yi Z, Tandiono M, Chew E, Dominguez J, et al. Targeted exome sequencing reveals homozygous TREM2 R47C mutation presenting with behavioral variant frontotemporal dementia without bone involvement. Neurobiol Aging. (2018) 68:160.e15-9. doi: 10.1016/j.neurobiolaging.2018.04.003

99. Peplonska B, Berdynski M, Mandecka M, Barczak A, Kuzma-Kozakiewicz $\mathrm{M}$, Barcikowska $\mathrm{M}$, et al. TREM2 variants in neurodegenerative disorders in the polish population. Homozygosity and compound heterozygosity in FTD patients. Amyotroph Later Sclero Frontotemp Degenerat. (2018) 19:40712. doi: 10.1080/21678421.2018.1451894

100. Redaelli V, Salsano E, Colleoni L, Corbetta P, Tringali G, Del Sole A, et al. Frontotemporal Dementia and chorea associated with a compound heterozygous TREM2 mutation. J Alzheimers Dis. (2018) 63:195201. doi: 10.3233/JAD-180018

101. Su WH, Shi S, Liu S, Wang X, Liu S, Ji Y. The rs75932628 and rs 2234253 polymorphisms of the TREM2 gene were associated with susceptibility to frontotemporal lobar degeneration in Caucasian populations. Ann Hum Genet. (2018) 82:177-85. doi: 10.1111/ahg.12241

102. Zhou SL, Tan CC, Hou XH, Cao XP, Tan L, Yu JT. TREM2 variants and neurodegenerative diseases: a systematic review and meta-analysis. $J$ Alzheimers Dis. (2019) 68:1171-84. doi: 10.3233/JAD-181038

103. Giraldo M, Lopera F, Siniard AL, Corneveaux JJ, Schrauwen I, Carvajal $\mathrm{J}$, et al. Variants in triggering receptor expressed on myeloid cells 2 are associated with both behavioral variant frontotemporal lobar degeneration and Alzheimer's disease. Neurobiol Aging. (2013) 34:2077.e118. doi: 10.1016/j.neurobiolaging.2013.02.016

104. Whitwell JL. FTD spectrum: Neuroimaging across the FTD spectrum. Progr Mol Biol Transl Sci. (2019) 165:187-223. doi: 10.1016/bs.pmbts.2019. 05.009

105. Gordon E, Rohrer JD, Fox NC. Advances in neuroimaging in frontotemporal dementia. J Neurochem. (2016) 138 (Suppl):193-210. doi: 10.1111/jnc.13656

106. Couto B, Manes F, Montañés P, Matallana D, Reyes P, Velasquez M, et al. Structural neuroimaging of social cognition in progressive non-fluent aphasia and behavioral variant of frontotemporal dementia. Front Hum Neurosci. (2013) 7:467. doi: 10.3389/fnhum.2013.00467

107. Lillo P, Caramelli P, Musa G, Parrao T, Hughes R, Aragon A, et al. Inside minds, beneath diseases: social cognition in amyotrophic lateral sclerosis-frontotemporal spectrum disorder. J Neurol Neurosurg Psychiatry. (2020) 91:1279-82. doi: 10.1136/jnnp-2020-324302

108. Mariano LI, Caramelli P, Guimarães HC, Gambogi LB, Moura MVB, Yassuda MS, et al. Can social cognition measurements differentiate behavioral variant frontotemporal dementia from alzheimer's disease regardless of apathy? $J$ Alzheimers Dis. (2020) 74:817-27. doi: 10.3233/JAD-190861

109. Moura MVB, Mariano LI, Teixeira AL, Caramelli P, de Souza LC. Social cognition tests can discriminate behavioral variant frontotemporal dementia from alzheimer's disease independently of executive functioning. Arch Clin Neuropsychol. (2020) acaa084. doi: 10.1093/arclin/acaa084

110. Baez S, Manes F, Huepe D, Torralva T, Fiorentino N, Richter F, et al. Primary empathy deficits in frontotemporal dementia. Front Aging Neurosci. (2014) 6:262. doi: 10.3389/fnagi.2014.00262

111. Fittipaldi S, Ibanez A, Baez S, Manes F, Sedeno L, Garcia AM. More than words: social cognition across variants of primary progressive aphasia. Neurosci Biobehav Rev. (2019) 100:263-84. doi: 10.1016/j.neubiorev.2019.02.020

112. Melloni M, Lopez V, Ibanez A. Empathy and contextual social cognition. Cogn Affect Behav Neurosci. (2014) 14:40725. doi: 10.3758/s13415-013-0205-3

113. Baez S, Couto B, Torralva T, Sposato LA, Huepe D, Montanes P, et al. Comparing moral judgments of patients with frontotemporal dementia and frontal stroke. JAMA Neurol. (2014) 71:11726. doi: 10.1001/jamaneurol.2014.347

114. Santamaría-García H, Baez S, Reyes P, Santamaría-García JA, SantacruzEscudero JM, Matallana D, et al. A lesion model of envy and schadenfreude: legal, deservingness and moral dimensions as revealed by neurodegeneration. Brain. (2017) 140:3357-77. doi: 10.1093/brain/awx269

115. Garcia-Cordero I, Sedeno L, de la Fuente L, Slachevsky A, Forno G, Klein $\mathrm{F}$, et al. Feeling, learning from and being aware of inner states: interoceptive dimensions in neurodegeneration and stroke. Philos Trans R Soc Lond B Biol Sci. (2016) 371:20160006. doi: 10.1098/rstb.2016.0006

116. Ibáñez A, Kuljiš RO, Matallana D, Manes F. Bridging psychiatry and neurology through social neuroscience. World Psychiatry. (2014) 13:148. doi: 10.1002/wps.20125

117. Ibáñez A, García AM, Esteves S, Yoris A, Muñoz E, Reynaldo L, et al. Social neuroscience: undoing the schism between neurology and psychiatry. Soc Neurosci. (2018) 13:1-39. doi: 10.1080/17470919.2016.1245214

118. Ibáñez A, García AM. Commentary: Cerebellar atrophy and its contribution to cognition in frontotemporal dementias. Front Aging Neurosci. (2018) 10:98-109. doi: 10.3389/fnagi.2018.00300

119. Ibáñez A, Manes F. Contextual social cognition and the behavioral variant of frontotemporal dementia. Neurology. (2012) 78:1354-62. doi: 10.1212/WNL.0b013e3182518375

120. Kumfor F, Ibañez A, Hutchings R, Hazelton JL, Hodges JR, Piguet O. Beyond the face: how context modulates emotion processing in frontotemporal dementia subtypes. Brain. (2018) 141:1172-85. doi: 10.1093/brain/awy002

121. Ibáñez A, Billeke $P$, De La Fuente L, Salamone P, García AM, Melloni M. Reply: towards a neurocomputational account of social dysfunction in neurodegenerative disease. Brain. (2017) 140:aww316. doi: 10.1093/brain/aww316

122. Melloni M, Billeke P, Baez S, Hesse E, De La Fuente L, Forno G, et al. Your perspective and my benefit: multiple lesion models of self-other integration strategies during social bargaining. Brain. (2016) 139:302240. doi: 10.1093/brain/aww231

123. Ibanez A, Schulte M. Situated minds: conceptual and emotional blending in neurodegeneration and beyond. Brain. (2020) 143:3523-5. doi: 10.1093/brain/awaa392

124. Ibáñez A. Insular networks and intercognition in the wild. Cortex. (2019) 115:341-4. doi: 10.1016/j.cortex.2019.01.024

125. Melloni M, Billeke P, Baez S, Fitipaldi S, Sedeno L, Garcia-Cordero A, et al. Do you have a strategy? Multimodal brain signatures of social bargaining in neurodegeneration and frontal stroke. Int J Psychophysiol. (2016) 108:1167. doi: 10.1016/j.ijpsycho.2016.07.347

126. Sedeño L, Couto B, García-Cordero I, Melloni M, Baez S, Sepúlveda JPM, et al. Brain network organization and social executive performance in frontotemporal dementia. J Int Neuropsychol Soc. (2016) 22:25062. doi: $10.1017 / \mathrm{S} 1355617715000703$ 
127. Friston KJ. Functional and effective connectivity in neuroimaging: a synthesis. Hum Brain Mapp. (1994) 2:56-78. doi: 10.1002/hbm.460020107

128. Freeman LC. Centrality in social networks conceptual clarification. Soc Netw. (1978) 1:215-39. doi: 10.1016/0378-8733(78)90021-7

129. Borroni B, Benussi A, Premi E, Alberici A, Marcello E, Gardoni $\mathrm{F}$, et al. Biological, neuroimaging, and neurophysiological markers in frontotemporal dementia: three faces of the same coin. J Alzheimers Dis. (2018) 62:1113-23. doi: 10.3233/JAD-170584

130. Moguilner S, García AM, Perl YS, Tagliazucchi E, Piguet O, Kumfor F, et al. Dynamic brain fluctuations outperform connectivity measures and mirror pathophysiological profiles across dementia subtypes: a multicenter study. NeuroImage. (2021) 225:117522. doi: 10.1016/j.neuroimage.2020.117522

131. Simrén J, Ashton NJ, Blennow K, Zetterberg H. An update on fluid biomarkers for neurodegenerative diseases: recent success and challenges ahead. Curr Opin Neurobiol. (2020) 61:29-39. doi: 10.1016/j.conb.2019.11.019

132. Yuan A, Rao MV, Veeranna, Nixon RA. Neurofilaments and neurofilament proteins in health and disease. Cold Spring Harbor Perspect Biol. (2017) 9:a018309. doi: 10.1101/cshperspect.a018309

133. Pijnenburg YAL, Verwey NA, van der Flier WM, Scheltens $P$, Teunissen CE. Discriminative and prognostic potential of cerebrospinal fluid phosphoTau/tau ratio and neurofilaments for frontotemporal dementia subtypes. Alzheimers Dement. (2015) 1:505-12. doi: 10.1016/j.dadm.2015.11.001

134. Steinacker P, Feneberg E, Weishaupt J, Brettschneider J, Tumani H, Andersen PM, et al. Neurofilaments in the diagnosis of motoneuron diseases: a prospective study on 455 patients. J Neurol Neurosurg Psychiatry. (2016) 87:12-20. doi: 10.1136/jnnp-2015-311387

135. Skillbäck T, Mattsson N, Blennow K, Zetterberg H. Cerebrospinal fluid neurofilament light concentration in motor neuron disease and frontotemporal dementia predicts survival. Amyotroph Later Sclero Frontotemp Degenerat. (2017) 18:397403. doi: 10.1080/21678421.2017.1281962

136. Gisslén M, Price RW, Andreasson U, Norgren N, Nilsson S, Hagberg L, et al. Corrigendum to: "Plasma concentration of the neurofilament light protein (NFL) is a biomarker of CNS injury in HIV infection: a cross-sectional study". EBioMedicine. (2016) 3:135-40. doi: 10.1016/j.ebiom.2015.11.036

137. Ljungqvist J, Zetterberg H, Mitsis M, Blennow K, Skoglund T. Serum neurofilament light protein as a marker for diffuse axonal injury: results from a case series study. J Neurotrauma. (2017) 34:11247. doi: $10.1089 /$ neu.2016.4496

138. Donker Kaat L, Meeter LH, Chiu WZ, Melhem S, Boon AJW, Blennow $K$, et al. Serum neurofilament light chain in progressive supranuclear palsy. Parkinsonism Relat Disord. (2018) 56:98-101. doi: 10.1016/j.parkreldis.2018.06.018

139. Rohrer JD, Woollacott IOC, Dick KM, Brotherhood E, Gordon E, Fellows A, et al. Serum neurofilament light chain protein is a measure of disease intensity in frontotemporal dementia. Neurology. (2016) 87:132936. doi: 10.1212/WNL.0000000000003154

140. Rojas JC, Karydas A, Bang J, Tsai RM, Blennow K, Liman V, et al. Plasma neurofilament light chain predicts progression in progressive supranuclear palsy. Ann Clin Transl Neurol. (2016) 3:216-25. doi: 10.1002/acn3.290

141. Steinacker P, Anderl-Straub S, Diehl-Schmid J, Semler E, Uttner I, Von Arnim CAF, et al. Serum neurofilament light chain in behavioral variant frontotemporal dementia. Neurology. (2018) 91:E1390-401. doi: 10.1212/WNL.0000000000006318

142. Meeter LH, Dopper EG, Jiskoot LC, Sanchez-Valle R, Graff C, Benussi L, et al. Neurofilament light chain: a biomarker for genetic frontotemporal dementia. Ann Clin Transl Neurol. (2016) 3:623-36. doi: 10.1002/acn3.325

143. van der Ende EL, Meeter LH, Poos JM, Panman JL, Jiskoot LC, Dopper EGP, et al. Serum neurofilament light chain in genetic frontotemporal dementia: a longitudinal, multicentre cohort study. Lancet Neurol. (2019) 18:110311. doi: 10.1016/S1474-4422(19)30354-0

144. De Jong D, Jansen RW, Pijnenburg YA, Van Geel WJ, Borm GF, Kremer HP, et al. CSF neurofilament proteins in the differential diagnosis of dementia. J Neurol Neurosurg Psychiatry. (2007) 78:9368. doi: 10.1136/jnnp.2006.107326
145. Landqvist Waldö M, Frizell Santillo A, Passant U, Zetterberg H, Rosengren L, Nilsson C, et al. Cerebrospinal fluid neurofilament light chain protein levels in subtypes of frontotemporal dementia. BMC Neurology. (2013) 13:54. doi: 10.1186/1471-2377-13-54

146. Sjögren M, Rosengren L, Minthon L, Davidsson P, Blennow K, Wallin A. Cytoskeleton proteins in CSF distinguish frontotemporal dementia from AD. Neurology. (2000) 54:1960-4. doi: 10.1212/WNL.54.10.1960

147. Scherling CS, Hall T, Berisha F, Klepac K, Karydas A, Coppola G, et al. Cerebrospinal fluid neurofilament concentration reflects disease severity in frontotemporal degeneration. Ann Neurol. (2014) 75:11626. doi: 10.1002/ana.24052

148. Skillbäck T, Farahmand B, Bartlett JW, Rosén C, Mattsson N, Nägga $\mathrm{K}$, et al. CSF neurofilament light differs in neurodegenerative diseases and predicts severity and survival. Neurology. (2014) 83:1945-53. doi: 10.1212/WNL.0000000000001015

149. De Muynck L, Van Dame P. Cellular effects of progranulin in health and disease. J Mol Neurosci. (2011) 45:549-60. doi: 10.1007/s12031-0119553-z

150. Jian J, Konopka J, Liu C. Insights into the role of progranulin in immunity, infection, and inflammation. J Leukocyte Biol. (2013) 93:199208. doi: 10.1189/jlb.0812429

151. Van Damme P, Van Hoecke A, Lambrechts D, Vanacker P, Bogaert E, Van Swieten J, et al. Progranulin functions as a neurotrophic factor to regulate neurite outgrowth and enhance neuronal survival. J Cell Biol. (2008) 181:3741. doi: $10.1083 /$ jcb. 200712039

152. Ghidoni R, Benussi L, Glionna M, Franzoni M, Binetti G. Low plasma progranulin levels predict progranulin mutations in frontotemporal lobar degeneration. Neurology. (2008) 71:12359. doi: 10.1212/01.wnl.0000325058.10218.fc

153. Meeter LHH, Patzke H, Loewen G, Dopper EGP, Pijnenburg YAL, van Minkelen R, et al. Progranulin levels in plasma and cerebrospinal fluid in granulin mutation carriers. Dement Geriatr Cogn Disord Extra. (2016) 6:330-40. doi: 10.1159/000447738

154. Morenas-Rodríguez E, Cervera-Carles L, Vilaplana E, Alcolea D, CarmonaIragui M, Dols-Icardo O, et al. Progranulin protein levels in cerebrospinal fluid in primary neurodegenerative dementias. J Alzheimers Dis. (2016) 50:539-46. doi: 10.3233/JAD-150746

155. Nicholson AM, Finch NCA, Thomas CS, Wojtas A, Rutherford NJ, Mielke $\mathrm{MM}$, et al. Progranulin protein levels are differently regulated in plasma and CSF. Neurology. (2014) 82:1871-8. doi: 10.1212/WNL.0000000000000445

156. Wilke C, Gillardon F, Deuschle C, Dubois E, A., Hobert M, et al. Serum levels of progranulin do not reflect cerebrospinal fluid levels in neurodegenerative disease. Curr Alzheimer Res. (2016) 13:654-62. doi: 10.2174/1567205013666160314151247

157. Wilke C, Gillardon F, Deuschle C, Hobert MA, Jansen IE, Metzger FG, et al. Cerebrospinal fluid progranulin, but not serum progranulin, is reduced in grn-negative frontotemporal dementia. Neurodegenerat Dis. (2017) 17:838. doi: 10.1159/000448896

158. Finch N, Baker M, Crook R, Swanson K, Kuntz K, Surtees R, et al. Plasma progranulin levels predict progranulin mutation status in frontotemporal dementia patients and asymptomatic family members. Brain. (2009) 132:583-91. doi: 10.1093/brain/awn352

159. Sleegers K, Brouwers N, Van Damme P, Engelborghs S, Gijselinck I, Van Der Zee J, et al. Serum biomarker for progranulin-associated frontotemporal lobar degeneration. Ann Neurol. (2009) 65:603-9. doi: 10.1002/ana.21621

160. Carecchio M, Fenoglio C, De Riz M, Guidi I, Comi C, Cortini F, et al. Progranulin plasma levels as potential biomarker for the identification of GRN deletion carriers. A case with atypical onset as clinical amnestic Mild Cognitive Impairment converted to Alzheimer's disease. J Neurol Sci. (2009) 287:291-3. doi: 10.1016/j.jns.2009.07.011

161. Rademakers R, Hutton M. The genetics of frontotemporal lobar degeneration. Curr Neurol Neurosci Rep. (2007) 7:43442. doi: 10.1007/s11910-007-0067-6

162. Steinacker P, Hendrich C, Sperfeld AD, Jesse S, Von Arnim CAF, Lehnert $\mathrm{S}$, et al. TDP-43 in cerebrospinal fluid of patients with frontotemporal lobar degeneration and amyotrophic lateral sclerosis. Arch Neurol. (2008) 65:1481-7. doi: 10.1001/archneur.65.11.1481 
163. Majumder V, Gregory JM, Barria MA, Green A, Pal S. TDP-43 as a potential biomarker for amyotrophic lateral sclerosis: a systematic review and metaanalysis. BMC Neurol. (2018) 18:90. doi: 10.1186/s12883-018-1091-7

164. Foulds P, McAuley E, Gibbons L, Davidson Y, Pickering-Brown SM, Neary D, et al. TDP-43 protein in plasma may index TDP-43 brain pathology in Alzheimer's disease and frontotemporal lobar degeneration. Acta Neuropathol. (2008) 116:141-6. doi: 10.1007/s00401-008-0389-8

165. Foulds PG, Davidson Y, Mishra M, Hobson DJ, Humphreys KM, Taylor M, et al. Plasma phosphorylated-TDP-43 protein levels correlate with brain pathology in frontotemporal lobar degeneration. Acta Neuropathol. (2009) 118:647-58. doi: 10.1007/s00401-009-0594-0

166. Suárez-Calvet M, Dols-Icardo O, Llad,ó A, Sánchez-Valle R, Hernández I, Amer G, et al. Plasma phosphorylated TDP-43 levels are elevated in patients with frontotemporal dementia carrying a C9orf72 repeat expansion or a GRN mutation. I Neurol Neurosurg Psychiatry. (2014) 85:68491. doi: 10.1136/jnnp-2013-305972

167. Paterson RW, Slattery CF, Poole T, Nicholas JM, Magdalinou NK, Toombs J, et al. Cerebrospinal fluid in the differential diagnosis of Alzheimer's disease: clinical utility of an extended panel of biomarkers in a specialist cognitive clinic. Alzheimers Res Ther. (2018) 10:32. doi: 10.1186/s13195-018-0361-3

168. Alcolea D, Vilaplana E, Suárez-Calvet M, Illán-Gala I, Blesa R, Clarimón J, et al. CSF sAPP $\beta$, YKL-40, and neurofilament light in frontotemporal lobar degeneration. Neurology. (2017) 89:178-88. doi: 10.1212/WNL.0000000000004088

169. Skillbäck T, Farahmand BY, Rosén C, Mattsson N, Nägga K, Kilander L, et al. Cerebrospinal fluid tau and amyloid- $\beta 1-42$ in patients with dementia. Brain. (2015) 138:2716-31. doi: 10.1093/brain/awv181

170. Struyfs H, Niemantsverdriet E, Goossens J, Fransen E, Martin JJ, de Deyn PP, et al. Cerebrospinal fluid P-tau181P: biomarker for improved differential dementia diagnosis. Front Neurol. (2015) 6:138. doi: 10.3389/fneur.2015.00138

171. Lin CH, Chiu SI, Chen TF, Jang JSR, Chiu MJ. Classifications of neurodegenerative disorders using a multiplex blood biomarkers-based machine learning model. Int J Mol Sci. (2020) 21:1-15. doi: 10.3390/ijms21186914

172. Karikari TK, Emeršič A, Vrillon A, Lantero-Rodriguez J, Ashton NJ, Kramberger MG, et al. Head-to-head comparison of clinical performance of CSF phospho-tau T181 and T217 biomarkers for Alzheimer's disease diagnosis. Alzheimers Dement. (2020) 175:755-67. doi: 10.1002/alz.12236

173. Palmqvist S, Janelidze S, Quiroz YT, Zetterberg H, Lopera F, Stomrud E, et al. Discriminative accuracy of plasma phospho-tau217 for alzheimer disease vs other neurodegenerative disorders. JAMA. (2020) 324:77281. doi: 10.1001/jama.2020.12134

174. Colangelo AM, Alberghina L, Papa M. Astrogliosis as a therapeutic target for neurodegenerative diseases. Neurosci Lett. (2014) 565:5964. doi: 10.1016/j.neulet.2014.01.014

175. Hol EM, Pekny M. Glial fibrillary acidic protein (GFAP) and the astrocyte intermediate filament system in diseases of the central nervous system. Curr Opin Cell Biol. (2015) 32:121-30. doi: 10.1016/j.ceb.2015.02.004

176. Heller C, Foiani MS, Moore K, Convery R, Bocchetta M, Neason M, et al. Plasma glial fibrillary acidic protein is raised in progranulin-associated frontotemporal dementia. J Neurol Neurosurg Psychiatry. (2020) 91:26370. doi: 10.1136/jnnp-2019-321954

177. Ishiki A, Kamada M, Kawamura Y, Terao C, Shimoda F, Tomita N, et al. Glial fibrillar acidic protein in the cerebrospinal fluid of alzheimer's disease, dementia with lewy bodies, and frontotemporal lobar degeneration. J Neurochem. (2016) 136:258-61. doi: 10.1111/jnc.13399

178. Oeckl P, Halbgebauer S, Anderl-Straub S, Steinacker P, Hussa AM, Neugebauer H, et al. Glial fibrillary acidic protein in serum is increased in alzheimer's disease and correlates with cognitive impairment. J Alzheimers Dis. (2019) 67:481-8. doi: 10.3233/JAD-180325

179. Oeckl P, Weydt P, Steinacker P, Anderl-Straub S, Nordin F, Volk AE, et al. Different neuroinflammatory profile in amyotrophic lateral sclerosis and frontotemporal dementia is linked to the clinical phase. J Neurol Neurosurg Psychiatry. (2019) 90:4-10. doi: 10.1136/jnnp-2018-318868

180. Heneka MT, Kummer MP, Latz E. Innate immune activation in neurodegenerative disease. Nat Rev Immunol. (2014) 14:46377. doi: $10.1038 /$ nri3705
181. Imamura K, Hishikawa N, Ono K, Suzuki H, Sawada M, Nagatsu T, et al. Cytokine production of activated microglia and decrease in neurotrophic factors of neurons in the hippocampus of lewy body disease brains. Acta Neuropathol. (2005) 109:141-50. doi: 10.1007/s00401-004-0919-y

182. Mrak RE, Griffin WST. Common inflammatory mechanisms in lewy body disease and alzheimer disease. J Neuropathol Exp Neurol. (2007) 66:6836. doi: 10.1097/nen.0b013e31812503e1

183. Pasqualetti G, Brooks DJ, Edison P. The role of neuroinflammation in dementias. Curr Neurol Neurosci Rep. (2015) 15:17. doi: 10.1007/s11910-015-0531-7

184. Cerami C, Iaccarino L, Perani D. Molecular imaging of neuroinflammation in neurodegenerative dementias: the role of in vivo PET imaging. Int $J \mathrm{Mol}$ Sci. (2017) 18:993. doi: 10.3390/ijms18050993

185. Miksztowicz V, Morales C, Zago V, Friedman S, Schreier L, Berg G. Effect of insulin-resistance on circulating and adipose tissue MMP-2 and MMP-9 activity in rats fed a sucrose-rich diet. Nutr Metab Cardiovasc Dis. (2014) 24:294-300. doi: 10.1016/j.numecd.2013.08.007

186. Sochocka M, Diniz BS, Leszek J. Inflammatory response in the CNS: friend or foe? Mol Neurobiol. (2017) 54:8071-89. doi: 10.1007/s12035-016-0297-1

187. Bright F, Werry EL, Dobson-Stone C, Piguet O, Ittner LM, Halliday GM, et al. Neuroinflammation in frontotemporal dementia. Nat Rev Neurol. (2019) 15:540-55. doi: 10.1038/s41582-019-0231-Z

188. Dembic Z. The cytokines of the immune system. Cytokines Immune Syst. (2015) 143-239. doi: 10.1016/B978-0-12-419998-9.00006-7

189. DiSabato DJ, Quan N, Godbout JP. Neuroinflammation: the devil is in the details. J Neurochem. (2016) 139:136-53. doi: 10.1111/jnc.13607

190. Cagnin A, Rossor M, Sampson EL, MacKinnon T, Banati RB. In vivo detection of microglial activation in frontotemporal dementia. Ann Neurol. (2004) 56:894-7. doi: 10.1002/ana.20332

191. Zhang J. Mapping neuroinflammation in frontotemporal dementia with molecular PET imaging. J Neuroinflammation. (2015) 12:108. doi: 10.1186/s12974-015-0236-5

192. Sjögren M, Folkesson S, Blennow K, Tarkowski E. Increased intrathecal inflammatory activity in frontotemporal dementia: pathophysiological implications. J Neurol Neurosurg Psychiatry. (2004) 75:1107-11. doi: 10.1136/jnnp.2003.019422

193. Rentzos M, Zoga M, Paraskevas GP, Kapaki E, Rombos A, Nikolaou C, et al. IL-15 is elevated in cerebrospinal fluid of patients with alzheimer's disease and frontotemporal dementia. J Geriatr Psychiatry Neurol. (2006) 19:114-7. doi: 10.1177/0891988706286226

194. Galimberti, D.aniela, Schoonenboom N, Scheltens P, Fenoglio C, Bouwman F, et al. Intrathecal chemokine synthesis in mild cognitive impairment and alzheimer disease. Archives of Neurology. (2006) 63:538-43. doi: 10.1001/archneur.63.4.538

195. Rentzos M, Paraskevas GP, Kapaki E, Nikolaou C, Zoga M, Rombos A, et al. Interleukin-12 is reduced in cerebrospinal fluid of patients with Alzheimer's disease and frontotemporal dementia. J Neurol Sci. (2006) 249:110-4. doi: 10.1016/j.jns.2006.05.063

196. Galimberti D, Bonsi R, Fenoglio C, Serpente M, Cioffi SMG, Fumagalli G, et al. Inflammatory molecules in frontotemporal dementia: cerebrospinal fluid signature of progranulin mutation carriers. Brain Behav Immun. (2015) 49:182-7. doi: 10.1016/j.bbi.2015.05.006

197. Galimberti D, Venturelli E, Fenoglio C, Guidi I, Villa C, Bergamaschini $\mathrm{L}$, et al. Intrathecal levels of IL-6, IL-11 and LIF in alzheimer's disease and frontotemporal lobar degeneration. J Neurol. (2008) 255:53944. doi: 10.1007/s00415-008-0737-6

198. Ahmed Z, Mackenzie IRA, Hutton ML, Dickson DW. Progranulin in frontotemporal lobar degeneration and neuroinflammation. $J$ Neuroinflammation. (2007) 4:7. doi: 10.1186/1742-2094-4-7

199. Martens LH, Zhang J, Barmada SJ, Zhou P, Kamiya S, Sun B, et al. Progranulin deficiency promotes neuroinflammation and neuron loss following toxininduced injury. J Clin Invest. (2012) 122:3955-9. doi: 10.1172/JCI63113

200. Miller ZA, Rankin KP, Graff-Radford NR, Takada LT, Sturm VE, Cleveland CM, et al. TDP-43 frontotemporal lobar degeneration and autoimmune disease. J Neurol Neurosurg Psychiatry. (2013) 84:95662. doi: 10.1136/jnnp-2012-304644

201. Jay TR, Von Saucken VE, Landreth GE. TREM2 in neurodegenerative diseases. Mol Neurodegenerat. (2017) 12:56. doi: 10.1186/s13024-017-0197-5 
202. Piccio L, Buonsanti C, Cella M, Tassi I, Schmidt RE, Fenoglio C, et al. Identification of soluble TREM-2 in the cerebrospinal fluid and its association with multiple sclerosis and CNS inflammation. Brain. (2008) 131:3081-91. doi: 10.1093/brain/awn217

203. Piccio L, Deming Y, Del-Águila JL, Ghezzi L, Holtzman DM, Fagan AM, et al. Cerebrospinal fluid soluble TREM2 is higher in Alzheimer disease and associated with mutation status. Acta Neuropathol. (2016) 131:92533. doi: 10.1007/s00401-016-1533-5

204. Kleinberger G, Yamanishi Y, Suárez-Calvet M, Czirr E, Lohmann E, Cuyvers E, et al. TREM2 mutations implicated in neurodegeneration impair cell surface transport and phagocytosis. Sci Transl Med. (2014) 6:243ra86. doi: 10.1126/scitranslmed.3009093

205. Bossù P, Salani F, Alberici A, Archetti S, Bellelli G, Galimberti D, et al. Loss of function mutations in the progranulin gene are related to pro-inflammatory cytokine dysregulation in frontotemporal lobar degeneration patients. $J$ Neuroinflammation. (2011) 8:76. doi: 10.1186/1742-2094-8-65

206. Roos P, von Essen MR, Nielsen TT, Johannsen P, Stokholm J, Bie AS, et al. Inflammatory markers of CHMP2B-mediated frontotemporal dementia. J Neuroimmunology. (2018) 324:136-42. doi: 10.1016/j.jneuroim.2018. 08.009

207. Miranda JJ, Herrera VM, Chirinos JA, Gómez LF, Perel P, Pichardo R, et al. Major cardiovascular risk factors in Latin America: a comparison with the United States. The Latin American Consortium of Studies in Obesity (LASO). PLoS ONE. (2013) 8:e54056. doi: 10.1371/journal.pone. 0054056

208. Aguirre-Acevedo DC, Lopera F, Henao E, Tirado V, Muñoz C, Giraldo M, et al. Cognitive decline in a colombian kindred with autosomal dominant alzheimer disease a retrospective cohort study. JAMA Neurol. (2016) 73:4318. doi: 10.1001/jamaneurol.2015.4851

209. Alladi S, Hachinski V. World dementia. Neurology. (2018) 91:26470. doi: 10.1212/WNL.0000000000005941

210. Ibáñez A, Sedeño L, García AM, Deacon RMJ, Cogram P. Editorial: human and animal models for translational research on neurodegeneration: challenges and opportunities from South America. Front Aging Neurosci. (2018) 10:95. doi: 10.3389/fnagi.2018.00095

211. Kalaria RN, Maestre GE, Arizaga R, Friedland RP, Galasko D, Hall K, et al. Alzheimer's disease and vascular dementia in developing countries: prevalence, management, risk factors. Lancet Neurol. (2008) 7:81226. doi: 10.1016/S1474-4422(08)70169-8

212. Reitz C, Mayeux R. Genetics of alzheimer's disease in caribbean hispanic and African American populations. Biol Psychiatry. (2014) 75:534-41). Elsevier USA. doi: 10.1016/j.biopsych.2013.06.003
213. Tosto G, Bird TD, Tsuang D, Bennett DA, Boeve BF, Cruchaga C, et al. Polygenic risk scores in familial alzheimer disease. Neurology. (2017) 88:1180-6. doi: 10.1212/WNL.0000000000003734

214. Parra MA. Overcoming barriers in cognitive assessment of alzheimer's disease. Dement Neuropsychol. (2014) 8:958. doi: 10.1590/S1980-57642014DN82000002

215. Abrevaya S, Fittipaldi S, García AM, Dottori M, Santamaria-Garcia H, Birba A, et al. At the heart of neurological dimensionality: cross-nosological and multimodal cardiac interoceptive deficits. Psychosom Med. (2020) 82:85061. doi: 10.1097/PSY.0000000000000868

216. Eyigoz E, Courson M, Sedeño L, Rogg K, Orozco-Arroyave JR, Nöth E, et al. From discourse to pathology: automatic identification of parkinson's disease patients via morphological measures across three languages. Cortex. (2020) 132:191-205. doi: 10.1016/j.cortex.2020.08.020

217. Gonzalez Campo C, Salamone PC, Rodríguez-Arriagada N, Richter F, Herrera E, Bruno D, et al. Fatigue in multiple sclerosis is associated with multimodal interoceptive abnormalities. Mult Sclero J. (2019) 26:184553. doi: $10.1177 / 1352458519888881$

218. Ipiña IP, Kehoe $P D$, Kringelbach $M$, Laufs $H$, Ibañez $A$, Deco G, et al. Modeling regional changes in dynamic stability during sleep and wakefulness. NeuroImage. (2020) 215:116833. doi: 10.1016/j.neuroimage.2020.116833

219. Torres-Prioris MJ, López-Barroso D, Càmara E, Fittipaldi S, Sedeño L, Ibáñez A, et al. Neurocognitive signatures of phonemic sequencing in expert backward speakers. Sci Rep. (2020) 10:10621. doi: 10.1038/s41598-020-67551-z

Disclaimer: The contents of this publication are solely the responsibility of the authors and do not represent the official views of these institutions.

Conflict of Interest: The authors declare that the research was conducted in the absence of any commercial or financial relationships that could be construed as a potential conflict of interest.

Copyright (C) 2021 Duran-Aniotz, Orellana, Leon Rodriguez, Henriquez, Cabello, Aguirre-Pinto, Escobedo, Takada, Pina-Escudero, Lopez, Yokoyama, Ibanez, Parra and Slachevsky. This is an open-access article distributed under the terms of the Creative Commons Attribution License (CC BY). The use, distribution or reproduction in other forums is permitted, provided the original author $(s)$ and the copyright owner(s) are credited and that the original publication in this journal is cited, in accordance with accepted academic practice. No use, distribution or reproduction is permitted which does not comply with these terms. 